ISSN : 0825-8643

\title{
Market Share and Price Rigidity
}

Isaac KLESHCHELSKI

Nicolas VINCENT

Cahier de recherche $n^{\circ}$ IEA-08-01

May 2007

Copyright (C) 2008 HEC Montréal.

Tous droits réservés pour tous pays. Toute traduction ou toute reproduction sous quelque forme que ce soit est interdite. Les textes publiés dans la série des Cahiers de recherche HEC n'engagent que la responsabilité de leurs auteurs.

La publication de ce Cahier de recherche a été rendue possible grâce à des subventions d'aide à la publication et à la diffusion de la recherche provenant des fonds de l'École des HEC.

Direction de la recherche, HEC Montréal, 3000, chemin de la Côte-Sainte-Catherine, Montréal (Québec) Canada H3T 2 A7. 


\title{
Market Share and Price Rigidity*
}

\author{
Isaac Kleshchelski ${ }^{\dagger}$ and Nicolas Vincent ${ }^{\ddagger}$
}

May 2007

\begin{abstract}
Survey evidence shows that the main reason why firms keep prices stable is that they are concerned about losing customers or market share. We construct a model in which firms care about the size of their customer base. Firms and customers form long-term relationships because consumers incur costs to switch sellers. In this environment, firms view customers as long-lived assets. We use a general equilibrium framework where industries and firms are buffeted by idiosyncratic marginal cost shocks. We obtain three main results. First, cost pass-through into prices is incomplete. Second, the degree of pass-through is an increasing function of the persistence of cost shocks. Third, there is a non-monotonic relationship between the size of switching costs and the rate of pass-through. In addition, we characterize the heterogenous response across industries to marginal cost shocks. The implications of our model are consistent with empirical evidence.
\end{abstract}

JEL classification: E30, L16

Keywords: Price Rigidity, Market Share, Customer Relations, Real Rigidities.

${ }^{*}$ We would like to thank Fancisco Buera, Larry Christiano, Martin Eichenbaum, Étienne Gagnon, Lyndon Moore, Éva Nagypál, Giorgio Primiceri, Nooman Rebei, Sergio Rebelo, Stephanie SchmittGrohé as well as seminar participants at Northwestern University, Yale University, UCSD, Brown University, Queen's University, Columbia University, HEC Montréal, University of Maryland, Université de Montréal, and the Bank of Canada for their insightful comments. All errors are our own. Vincent would like to thank the Social Sciences and Humanities Research Council of Canada for financial support.

${ }^{\dagger}$ Kellogg School of Management, Northwestern University, email: ikleshchelski@kellogg.northwestern.edu

${ }^{\ddagger}$ HEC Montréal, CIRPÉE, email: nicolas.vincent @hec.ca 


\section{Introduction}

This paper analyzes real rigidities in firms' pricing decisions. We focus on the following phenomenon: pass-through from marginal cost to prices is often incomplete. The most obvious example of "incomplete pass-through" is the relatively small impact of exchange rate changes on the retail price of imported goods. There is also evidence of incomplete pass-through from wholesale to retail prices. ${ }^{1}$ Using aggregate time-series data, Bils (1987), Rotemberg and Woodford (1999) and Altig, Christiano, Eichenbaum and Linde (2005) argue that prices are less volatile than marginal cost.

There are many theoretical reasons proposed as to why prices are more stable than marginal cost. ${ }^{2}$ In surveys, firms report that the main reason they wish to keep prices stable is that they are concerned about losing customers or market share. In contrast, firms give much less weight to factors such as menu costs and costly information which are often emphasized as explanations for price rigidity.

The interaction between firms and customers has received surprisingly little attention in the macroeconomic literature. ${ }^{3}$ The standard framework of monopolistic competition used in macro models is the one developed by Dixit and Stiglitz (1977). Despite its many virtues, it cannot generate incomplete cost pass-through in the absence of nominal frictions. Moreover, in this model there is no distinction between the extensive margin of sales (the number of customers) and the intensive margin (the quantity sold per customer).

We construct a model in which firms care about the size of their customer base.

\footnotetext{
${ }^{1}$ Examples of incomplete pass-through exist in a variety of contexts: see Campa and Goldberg (2002) and Burstein, Eichenbaum and Rebelo (2005) for the case of exchange rates; Besanko, Dubé and Gupta (2005) on the relationship between wholesale and retail prices; Borenstein, Cameron, Gilbert (1992) for gas prices; Neumark and Sharpe (1992) for interest rates; and Peltzman (2000) for a variety of sectors.

${ }^{2}$ See for example Ball and Romer (1990) and the references therein, modern DSGE models with nominal rigidities (Christiano, Eichenbaum and Evans (2005) and Rotemberg and Woodford (1997)), non-constant elasticities of consumer demand (e.g. Dotsey and King (2005)), or costly information (Wiederholt and Mackowiak (2006)).

${ }^{3} \mathrm{~A}$ notable exception is Rotemberg (2005), where firms are reluctant to raise prices if they fear that consumers will view the new price as "unfair". Schmitt-Grohé, Uribe and Ravn (2006) study a model with habit persistence at the good level which can also be related to ours. Other studies include Amano and Hendry (2003) and Ireland (1998). They focus respectively on aggregate inflation persistence and the markup patterns over the business cycle.
} 
Consumers decide how much of a good to consume and which firm to buy it from. Firms and customers form long-term relationships because consumers incur costs to switch sellers. In this environment firms view customers as long-lived assets. Consequently, they face an intertemporal tradeoff between increasing current profits and building market share for the future.

We embed our model of imperfect competition into a general equilibrium framework where industries and firms are buffeted by idiosyncratic marginal cost shocks. We obtain three main results. First, pass-through is incomplete. Second, the degree of pass-through is an increasing function of the persistence of cost shocks. Third, there is a non-monotonic relationship between the size of switching costs and the rate of pass-through. When switching costs are low, customers are likely to leave in the future and are therefore of little value to the firm. Consequently, firms pass-through a large fraction of marginal cost changes into their prices. As switching costs increase, customers become more attached and valuable, and pass-through falls. However, when switching costs are so high that customers never switch, the extensive margin is irrelevant and prices move one for one with marginal costs.

The third result implies that there is interesting heterogeneity in the price response across industries following marginal cost shocks. We argue that the model's predictions are in line with the available empirical evidence. Price-setting surveys show that firms which are most concerned about customer relations and with the highest proportion of repeat customers report more stable prices.

Our results are of interest to macroeconomists for at least two reasons. First, to understand how firms respond to idiosyncratic shocks is inherently interesting given the prevalence of such shocks. Second, it is well known that nominal frictions must be combined with real rigidities in order for nominal shocks to have significant and persistent real effects.

The outline of the paper is as follows. Section 2 provides an overview of the empirical evidence relevant to our paper. Sections 3 and 4 describe the economic environment as well as the maximization problems faced by households and firms, and the predictions of the model in a static environment. Section 5 presents our findings for the dynamic environment and explains the intuition behind the results. Section 6 concludes. 


\section{Motivating Evidence}

As the list of candidate theories for price rigidity expands, some researchers took to the task of asking firms directly about their pricing behavior. In these studies, managers are asked to rank or assign scores to a number of popular economic theories which are expained to them in non-technical terms. While one might suspect that wording and interpretation issues could hinder the usefulness of such exercise, there is in fact remarkable homogeneity in findings across countries.

Table 1 reports some evidence from Fabiani et al. (2005). It gathers and summarizes the results from a number of price-setting surveys regarding the relative importance of various theories of price rigidity. The striking feature behind this evidence is the importance that firms attach to factors linked to "customer relations", despite the fact that the actual theory this category refers to may differ across surveys. For example, it includes the implicit contract theory of Okun (1981) where firms keep prices stable in order to build long-term relationships with their customers; the desire of sellers to maintain market share; or their fear of antagonizing customers. Blinder et al. (1998) observe that firms often volunteer similar explanations when asked openended questions on price rigidity. While it might be difficult to determine which of these variants is most relevant, our emphasis on factors related to customer base and market share appears clearly in line with firms' actual concerns.

TABLE 1

THEORIES BEHIND PRICE RIGIDITY

\begin{tabular}{l|ccccccccccc}
\hline \hline & Euro & US & CA & SW & UK & BE & ES & FR & NL & AT & PT \\
\hline Customer relations & 1 & 4 & 2 & 1 & 5 & 1 & 1 & 4 & 1 & 1 & 1 \\
Menu costs & 8 & 6 & 10 & 11 & 11 & 9 & 6 & 6 & 7 & 8 & 7 \\
Costly information & 9 & - & 10 & 13 & - & 8 & 7 & - & - & 7 & - \\
\hline \# of theories & 10 & 12 & 11 & 13 & 11 & 10 & 9 & 7 & 8 & 10 & 9 \\
\hline
\end{tabular}

Note: Rank of different theories based on firm surveys.

Source: Fabiani et al. (2005) 
Paradoxically, the two mechanisms which have probably garnered the most attention in the state-dependent literature on price stickiness are considered less important by firms. When managers are asked whether price rigidity might be the product of menu costs or costly information gathering, they invariably rank such theories very low. This result is in line with the case study of Zbaracki, Ritson, Levy, Dutta and Bergen (2004): they find that physical menu costs are very small, while customer costs represent $75 \%$ of the cost of changing prices. However, this is not to say that those two theories are irrelevant: Ball and Romer (1990) have shown that even small menu costs coupled with some real rigidity, in the spirit of the one we are studying in this paper, can generate significant nominal price rigidity. Nonetheless, from the perspective of price setters, they do not appear to be the main impediments to price flexibility.

There is also evidence that the degree of price rigidity is related to customer base concerns. The survey on price-setting conducted in Canada by Amirault, Kwan and Wilkinson (2006) offers evidence that there is a significant correlation between the importance of customer relations and price stickiness. They report that "customer relations costs have a very high level of acknowledgement among firms with the stickiest prices. Seventy-six per cent of firms who change their prices only once or not at all during the year recognize this factor as a source of price rigidity" compared with $37 \%$ who adjust prices more than 52 times a year. This difference is statistically significant.

Not surprisingly, firms with a higher fraction of repeat customers are also those who are more concerned about factors linked to customer relations. For example, in the survey of Apel, Friberg and Hallsten (2005), "the mean score given to the implicit contract theory is 3.06 [on a scale of 1 to 4] for firms with at least $90 \%$ of sales to regular customers, whereas the mean score is 1.94 for firms with less than $10 \%$ of their sales to regular customers." Similar findings emerge from the studies by Hall, Walsh and Yates (1997) for the UK and Kwapil, Baumgartner and Scharler (2005) for Austria. In addition, there is evidence that firms with a higher proportion of repeat customers tend to have more rigid prices. Aucremanne and Druant (2005) find that $43 \%$ of sticky-price firms have more than $50 \%$ of repeat customers, versus $28 \%$ for flexible-price firms. Similarly, Hall et al. (1997) report "that companies with 
a greater proportion of long-term customer relationships reviewed and changed prices less frequently than the others."

Recent laboratory studies have also found evidence that price rigidity is more pronounced in the customer market than in an anonymous market. Cason and Friedman (2002) report that in their experiment, when sellers and buyers enter longterm relationships (here because customers face some costs of switching supplier), sellers will often absorb a portion of their cost changes in order to preserve their customer base. Similarly, Renner and Tyran (2004) find that "many sellers do not respond to the cost shock by increasing prices [...] because they hope to reap the gains from trading with loyal customers in the remaining periods of the game."

A number of studies have recently looked into the behavior of individual prices. Bils and Klenow (2004) analyze a dataset of prices collected by the BLS for the U.S. economy, and similar research has been conducted in a number of European economies (Dhyne et al. (2005)) and other countries (e.g. Gagnon (2006) and Lach and Tsiddon (1992)). Despite differences across datasets, some robust findings emerge. First, there is overwhelming evidence that most products exhibit a significant degree of price stickiness: the average monthly frequency of price adjustment is 25 percent in the US and 15 percent in the Euro area. There is, however, considerable heterogeneity in price rigidity along various dimensions. Across categories, services invariably display the stickiest prices, whereas energy goods and unprocessed food prices are the most flexible. Even within services, differences in price rigidity remain significant: prices are substantially more rigid in sectors which are typically characterized by longterm relationships between firms and customers (e.g. barbers, beauty services, legal and medical services, etc.). In addition, studies find that traditional corner shops, which arguably have more stable and longer-lived business relationships with their customers, display a significantly higher degree of price rigidity than supermarkets, even after controlling for the type of good. ${ }^{4}$ We develop a theory consistent with such findings.

We analyze firms' pricing decisions following sector- and firm-level marginal cost

\footnotetext{
${ }^{4}$ See for example Baudry, Le Bihan, Sevestre and Tarrieu (2004). They find that for their reference product, supermarkets are on average twice as likely to change their prices each month compared to traditional corner shops or service outlets.
} 
shocks. As pointed out by Golosov and Lucas (2003) and Klenow and Willis (2006), datasets of individual prices show little economy-wide synchronisation of price changes, significant fluctuations in relative prices, as well as price drops which are almost as common as price increases, suggesting a predominant role for non-aggregate shocks. Fabiani et al. (2005) present evidence from a number of European countries which suggests that there is also little synchronization within sectors. They use a statistical measure which ranges between 0 and 1 , with 1 indicating perfect synchronisation, and find that the median value across sectors ranges from 0.13 to 0.48 depending on the country. However, Veronese, Fabiani, Gattulli and Sabbatini (2005) using Italian data show that this conclusion is highly dependent on the treatment of geography. When product categories also take into account the geographical location of price quotes (e.g. milk in Rome, milk in Milan, etc.), they find that prices are substantially more synchronised: the median synchronisation ratio rises from 0.24 to 0.46 . Their finding is consistent with the observation that synchronisation is higher for smaller countries, where markets are more geographically integrated. This evidence suggests a significant role for sectoral shocks in addition to firm-specific disturbances.

There are a number of conclusions we draw from the evidence in this section. First, a wide range of surveys find that firms consider factors linked to their customer base to be the main rationale behind keeping prices stable. They also reveal that there is a strong relation between the importance of customer relations, the proportion of repeat customers, and the degree of price stickiness. We show that services, and in particular those sectors where buyer/seller relationships are important, display the most rigid prices. In the next section, we describe a model that can rationalize these findings. 


\section{A macro model with market share dynamics}

We develop a tractable model based on micro-foundations in which firms are rationally concerned about their market share position. Our model builds on the work of Ball and Romer (1990) and extends it to a dynamic version based on the standard imperfect competition framework. ${ }^{5}$ As such, it collapses to the well-known Dixit-Stiglitz model in certain special cases. The central mechanism is related to the customer market literature (e.g. Phelps and Winter (1970)) under imperfect information (see Stiglitz (1979) and Woglom (1982)).

The environment is comprised of households who consume and provide labor, and firms who produce consumption goods. However, unlike a standard model, the consumption decision here is two-dimensional: households decide not only how much of a particular good to consume, but also which firm to buy it from. The decision to switch supplier is a function of the relative price and a switching cost. The ensuing customer base dynamics render the firm's problem intertemporal.

\subsection{Households}

The economy is composed of a continuum of sectors, each producing a good indexed by $i \in[0,1]$. In each sector, there is an infinite number of firms, each selling a distinct brand $k \in[0,1] .{ }^{6}$ While goods are imperfect substitutes, brands are homogenous and perfectly substituable.

Households are infinitely lived and denoted by $j \in[0,1] \times[0,1]$. Each household $j$ consumes only one brand $k$ of good $i .^{7}$ It derives disutility from labor $l^{j}$ and utility from a basket of goods $\tilde{c}^{j}$, and solves the following problem:

\footnotetext{
${ }^{5}$ The static version of Ball and Romer (1990) is used to investigate the interaction of real and nominal rigidities. See also Ireland (1998) for a related extension based on a one-good economy. The objective there is to study the impact of customer flows on the cyclical behavior of markups.

${ }^{6}$ Throughout the paper we use the terms "supplier", "producer", "firm" and "seller" interchangeably. Also, we sometimes refer to a "sector" when talking about the set of firms which produce a similar good $i$.

${ }^{7}$ This is an assumption of the model. However, because the brands are perfect substitutes $e x$ ante, the introduction of an infinitesimal cost of consuming a given brand would make it an optimal choice for the household.
} 


$$
\begin{gathered}
\max U_{0}^{j}=E_{0} \sum_{t=0}^{\infty} \beta^{t} u\left(\tilde{c}_{t}^{j}, l_{t}^{j}\right) \\
u\left(\tilde{c}_{t}^{j}, l_{t}^{j}\right)=\frac{\left(\tilde{c}_{t}^{j}\right)^{1-\sigma}}{1-\sigma}-\eta \frac{\left(l_{t}^{j}\right)^{1+\epsilon}}{1+\epsilon} \\
\tilde{c}_{t}^{j}=\left\{\int_{0}^{1}\left[\left(\delta_{i t}^{j}\right)^{-s_{i t}^{j}} c_{i t}^{j}\right]^{\frac{\gamma-1}{\gamma}} d i\right\}^{\frac{\gamma}{\gamma-1}} \\
\int_{0}^{1} p_{i t}^{j} c_{i t}^{j} d i+E_{0} r_{t+1} b_{t+1}^{j}=b_{t}^{j}+w_{t} l_{t}^{j}+\Pi_{t}
\end{gathered}
$$

where $E$ is the expectation operator, $\gamma$ is the elasticity of substitution between varieties, and $\sigma$ is the inverse of the elasticity of intertemporal substitution, or risk aversion parameter. The household supplies homogenous labor and earns the economywide nominal wage rate $w_{t}$. Households also have access to complete state-contingent claims markets. The stochastic discount factor is given by $r_{t+1}$ such that $E_{t} r_{t+1} b_{t+1}^{j}$ is the price at time 0 of a random payment $b_{t+1}^{j}$ in period $t+1$ (we also impose a no-Ponzi-game constraint). Each household receives an equal share of the period $t$ profits from the firms, $\Pi_{t}$. To avoid confusion, we denote by $\tilde{x}$ any variable $x$ which refers to the aggregate basket of goods.

Our consumption aggregator (3.1) takes into account the switching decision of the household: we write $s_{z t}^{j}=1$ if household $j$ switches seller for good $z$ at time $t$ and 0 otherwise. Clearly, the endogenous choice by the consumer to leave his current seller will be a function of the parameter $\delta_{i t}^{j}$, which quantifies the utility implications for household $j$ of changing the brand of good $i$ at time $t$ : ceteris paribus, a higher $\delta_{i t}^{j}$ reduces the incentive of the consumer to switch brands. We will refer to $\delta$ as a switching cost. At time $t$, the household draws a new independently and identically distributed idiosyncratic switching cost $\delta_{i t}^{j} \in[\underline{\delta}, \bar{\delta}], \bar{\delta} \geq \underline{\delta}>0$ from a known time-invariant continuous distribution with a cumulative distribution function 
$F$ and probability density function $f .8$

We do not rule out $\delta<1$ : there are instances when a customer will find it optimal to leave his current seller even if the relative price is low. That brand switching occurs for non-price reasons is widely acknowledged in the marketing literature (see for example Ganesh, Arnold and Reynolds (2000) and Keaveney (1995)). Reasons may include poor product and service quality, inconvenience, relationship quality, etc. We model these exogenous factors by allowing for low values of the switching $\operatorname{cost} \delta$. Consequently, our model implies that in steady state a non-zero mass of customers switches suppliers every period.

The timing of household $j$ 's sequence of decisions for the purchase of a typical good $i$ is as follows: In period $t-1$, household $j$ bought good $i$ from one, and only one, supplier $k$ which we call his "home seller". At time $t$, after drawing a switching cost, $\delta_{i t}^{j}$, the household observes the price $p_{i t}(k)$ set by his home seller as well as the distribution of prices of other brands of good $i$ over the unit interval. We denote the continuum of all sector prices as $\left\{p_{i t}(l)\right\}_{l \in[0,1]}$. The consumer can then decide to remain with his home seller and pay $p_{i t}(k)$, in which case we denote his decision by $s_{i t}^{j}=0$. Conversely, he can opt to switch and be randomly assigned to a different seller $\left(s_{i t}^{j}=1\right)$. Random matching is consistent with our assumption of imperfect information (households only know the distribution of sector prices). A consumer can only switch once per period. Finally, he decides the quantity of good $i$ to buy, $c_{i t}^{j}$.

From the household's problem, the optimality conditions with respect to $l_{t}^{j}$ and $b_{t+1}^{j}$ are standard:

$$
\begin{gathered}
\eta\left(l_{t}^{j}\right)^{\epsilon}=\mu_{t}^{j} w_{t} \\
\mu_{t}^{j} E_{t} r_{t+1}=\beta E_{t} \mu_{t+1}^{j} .
\end{gathered}
$$

\footnotetext{
${ }^{8} \mathrm{An}$ alternative interpretation would be that the switching cost is constant over time and common across households, but that consumers are hit by i.i.d. taste shocks. The sum of the two would correspond to $\delta$.
} 
The first-order condition with respect to good $i$ yields:

$$
\left(\tilde{c}_{t}^{j}\right)^{\frac{1}{\gamma}-\sigma}\left(\delta_{i t}^{j}\right)^{\frac{s_{i t}^{j}(1-\gamma)}{\gamma}}\left(c_{i t}^{j}\right)^{-\frac{1}{\gamma}}=\mu_{t}^{j} p_{i t}^{j}
$$

where $\mu_{t}^{j}$ is the multiplier on the household's budget constraint. We can rewrite the budget constraint as:

$$
\tilde{p}_{t}^{j} \tilde{c}_{t}^{j}+E_{0} r_{t+1} b_{t+1}^{j}=b_{t}^{j}+w_{t} l_{t}^{j}+\Pi_{t}
$$

where the price index for the basket of goods $\tilde{p}_{t}^{j}$ is household-specific. The first-order condition with respect to $\tilde{c}_{t}^{j}$ yields:

$$
\left(\tilde{c}_{t}^{j}\right)^{-\sigma}=\mu_{t}^{j} \tilde{p}_{t}^{j}
$$

Using the optimality conditions (3.4) and (3.5), we get a general demand function of household $j$ for good $i$ as a function of the switching decision $s_{i t}^{j}$ :

$$
c_{i t}^{j}=\left\{\begin{array}{cc}
\left(\frac{p_{i t}^{j}}{\tilde{p}_{t}}\right)^{-\gamma} \tilde{c}_{t}^{j} & \text { if } s_{i t}^{j}=0 \\
\left(\delta_{i t}^{j}\right)^{1-\gamma}\left(\frac{p_{i t}^{j}}{\tilde{p}_{t}}\right)^{-\gamma} \tilde{c}_{t}^{j} & \text { if } s_{i t}^{j}=1 .
\end{array}\right.
$$

If firm $k$ is the home seller, then the relevant price when the household decides to stay is $p_{i t}^{j}=p_{i t}(k)$, whereas it is a random draw from the set of prices $\left\{p_{i t}(l)\right\}_{l \in[0,1]}$ in the event of a switch. As each consumer faces different prices, the aggregate price index $\tilde{p}_{t}^{j}$ is household specific. However, in the symmetric equilibrium, this will no longer be the case.

\subsubsection{Switching decision}

In order to facilitate the exposition of the switching decision of the consumer, we consider a recursive representation of the household's problem. Since there is a continuum of goods we can focus on the choice to switch in one sector $i$ in isolation and make abstraction of the other variables which are invariant to the switching decision.

We denote the sequence of future prices charged by firm $k$ as $p_{i}^{t}(k)=\left\{p_{i t+z}(k)\right\}_{z=0}^{\infty}$. 
As we need to keep track of the distribution of prices, we write the collection of price sequences for good $i$ as $\left\{p_{i}^{t}(l)\right\}_{l \in[0,1]}$. We can then define the value for a consumer of staying $\left(s_{i t}=0\right)$ with his home seller $k$ as: ${ }^{9}$

$$
V_{0}\left[\left\{p_{i}^{t}\right\}, p_{i}^{t}(k)\right]=U\left[c_{i t}\left(p_{i t}(k)\right)\right]+\beta E \max \left[\begin{array}{c}
V_{0}\left[\left\{p_{i}^{t+1}\right\}, p_{i}^{t+1}(k)\right], \\
V_{1}\left[\left\{p_{i}^{t+1}\right\}, \delta_{i t+1}\right]
\end{array}\right]
$$

Recall that when making the switching decision, the household has already observed the price of its current supplier, hence the instantaneous utility at time $t$ is known. The expression for the continuation value indicates that the consumer will face a similar choice tomorrow. The expected value of leaving $\left(s_{i t}=1\right)$ the home seller is given by:

$V_{1}\left[\left\{p_{i}^{t}\right\}, \delta_{i t}\right]=\int_{0}^{1} M_{i t-1}(l)\left\{U\left[c_{i t}\left(p_{i t}(l), \delta_{i t}\right)\right] d l+\beta E \max \left[\begin{array}{c}\left.V_{0}\left[\left\{p_{i}^{t+1}\right\}, p_{i}^{t+1}(l)\right],\right] \\ V_{1}\left[\left\{p_{i}^{t+1}\right\}, \delta_{i t+1}\right]\end{array}\right]\right\} d l$.

The expression corresponds to an expected value because the consumer only knows the distribution of sectoral prices at the time of switching. Once he decides to switch, we assume that the probability of being matched with seller $l$ is proportional to its previous period's market share, which we denote as $M_{i t-1}(l)$. This is similar to Phelps and Winter (1970), and simply implies that big firms will get a larger fraction of the mass of switchers. ${ }^{10}$ In addition, the realized switching cost is now an inherent part of the value function since it determines the utility at time $t$.

The threshold switching cost, denoted by $\widehat{\delta}_{i t}$, is the one which makes the consumer indifferent between switching and staying:

$$
V_{0}\left[\left\{p_{i}^{t}\right\}, p_{i}^{t}(k)\right]=V_{1}\left[\left\{p_{i}^{t}\right\}, \widehat{\delta}_{i t}\right] .
$$

That is, all customers for which $\delta_{i t}^{j}>\widehat{\delta}_{i t}$ will remain with their home supplier of good $i$ while all those with $\delta_{i t}^{j} \leq \widehat{\delta}_{i t}$ will find it optimal to switch. Notice that

\footnotetext{
${ }^{9}$ While $p_{i}^{t}(k)$ is technically part of $\left\{p_{i}^{t}\right\}$, we write it separately to emphasize that the consumer knows only the price charged by his home seller, as well as the distribution of prices within the sector.

${ }^{10}$ It is easy to verify that the condition $\int_{0}^{1} M_{i t-1}(l) d l=1$ is satisfied every period.
} 
the existence of positive switching costs will create behavior akin to habit persistence at the brand/product level. One could therefore see this mechanism as a possible micro foundation for the good-level habit formation studied by Ravn et al. (2006) and Nakamura and Steinsson (2007).

\subsection{Firms}

A firm in this environment is indexed by a pair $g \in G$ indicating the good and the brand, where $G \equiv\{(i, k): i \in[0,1], k \in[0,1]\}$. Clearly, the firm is atomistic and will take the aggregate variables as well as the decisions of its competitors as given. As mentioned in the previous section, $M_{i t}(k)$ corresponds to the mass of customers of firm $(i, k)$ at time $t$. We also refer to $M_{i t}(k)$ as the "market share" or "customer base".

Consider the problem of a seller $k$ of good $i$ who comes into period $t$ with a market share $M_{i t-1}(k)$. The firm observes the realization of a sector-specific productivity shock at time $t$ which is common to all producers in sector $i$ and ponders the possibility of changing its price $p_{i t}(k) .{ }^{11}$ Based on its pricing decision, the firm's current customers then optimally decide between staying or leaving their home seller. When changing its relative price supplier $k$ affects the threshold switching cost $\widehat{\delta}_{i t}(k)$ : if it increases its price more customers will now find it optimal to switch brand, which raises $\widehat{\delta}_{i t}(k)$. This will lead to a depletion of the firm's customer base available next period. Note that this dimension is entirely missing from Ball and Romer (1990): in their framework, sellers and buyers are randomly matched every period, with the consequence that any change in the mass of customers today has no impact on future profits.

To determine the evolution of market share, we define two groups of customers over which the firm is not allowed to price discriminate. The first group corresponds to repeat customers: it consists of consumers who bought from firm $k$ at $t-1$ and who, after observing firm $k$ 's price as well as the distribution of prices within sector $i$, have decided against switching. Their mass corresponds to the portion of customers

\footnotetext{
${ }^{11}$ In Section 5.2, we also consider firm-specific shocks under a special case.
} 
from last period, $M_{i t-1}(k)$, who draw a switching cost larger than $\widehat{\delta}_{i t}(k)$ :

$$
M_{i t}^{R}(k)=M_{i t-1}(k)\left[1-F\left(\widehat{\delta}_{i t}(k)\right)\right]
$$

The assumption that customers have to draw a new i.i.d. switching cost every period is crucial here: if we did not impose this assumption, we would need to keep track of the distribution of current customers, indexed by their respective $\delta$. Instead, the mass of customers that the firm keeps from one period to the next is distributed according to the time-invariant distribution $F$.

The second group is composed of new customers who randomly arrive from other sellers. Consistent with the household problem, the rate at which a firm attracts new customers is proportional to its previous period's market share. ${ }^{12}$ Since consumers are randomly matched and are not allowed to switch more than once per period, firm $k$ 's actions today have no impact on the arrival rate of customers in period $t .{ }^{13}$ The mass of new customers is given by:

$$
M_{i t}^{N}(k)=M_{i t-1}(k) \int_{0}^{1} M_{i t-1}(l) F\left(\widehat{\delta}_{i t}(l)\right) d l
$$

and the law of motion of the customer base at time $t$ is: ${ }^{14}$

$$
\begin{aligned}
M_{i t}(k) & =M_{i t}^{R}(k)+M_{i t}^{N}(k) \\
& =M_{i t-1}(k)\left[1-F\left(\widehat{\delta}_{i t}(k)\right)+\int_{0}^{1} M_{i t-1}(l) F\left(\widehat{\delta}_{i t}(l)\right) d l\right] .
\end{aligned}
$$

Next, we turn our attention to the demand schedule faced by seller $(i, k)$. The

\footnotetext{
${ }^{12}$ Such an assumption implies that the growth rate of the market share is independent of the size of the firm.

${ }^{13}$ In an Appendix availble upon request, we relax this assumption and notice that the properties of the model are qualitatively unchanged.

${ }^{14}$ It is easy to verify that given the initial condition $\int_{0}^{1} M_{i,-1}(k) d k=1$, it must be that (1) the mass of switchers is equal to the mass of new customers, and that (2) $\int_{0}^{1} M_{i, t}(k) d k=1, \forall t \geq 0$.
} 
quantity sold to repeat customers is:

$$
c_{i t}^{R}(k)=M_{i t-1}(k) \int_{\widehat{\delta}_{i t}(k)}^{\infty}\left[\int_{j: \delta_{i t}^{j}=\delta}\left(\frac{p_{i t}(k)}{\tilde{p}_{t}^{j}}\right)^{-\gamma} \tilde{c}_{t}^{j} d j\right] d \delta
$$

Since the aggregate price and consumption indexes are household specific, we need to explicitly integrate over each household. Notice that the switching costs drawn do not enter this expression, since by opting to stay with their home seller, repeat customers avoid suffering any utility penalty from switching. The pricing decision has two effects on the demand of repeat customers. First, it impacts the intensive margin through the term $\left(\frac{p_{i t}(k)}{\tilde{p}_{t}^{j}}\right)^{-\gamma} \tilde{c}_{t}^{j}$. Second, it influences the extensive margin by affecting the lower bound of the outer integral, $\widehat{\delta}_{i t}(k)$. Next, we can write the demand from new customers

$$
c_{i t}^{N}(k)=M_{i t-1}(k) \int_{0}^{1} c_{i t-1}^{L}(l) d l
$$

where $c_{i t-1}^{L}(l)$ is the consumption of customers leaving seller $l$

$$
c_{i t-1}^{L}(l)=M_{i t-1}(l) \int_{\underline{\delta}}^{\widehat{\delta}_{i t}(l)}\left[\int_{j: \delta_{i t}^{j}=\delta}\left(\delta_{i t}^{j}\right)^{1-\gamma}\left(\frac{p_{i t}(k)}{\tilde{p}_{t}^{j}}\right)^{-\gamma} \tilde{c}_{t}^{j} d j\right] d \delta .
$$

Unlike the case of repeat customers the price-setting decision here only impacts the intensive margin. The total demand schedule faced by firm $(i, k)$ is then simply the sum of expressions (3.9) and (3.10):

$$
c_{i t}(k)=c_{i t}^{R}(k)+c_{i t}^{N}(k) .
$$

The dynamic problem of a supplier $k$ of good $i$ is to solve the following problem:

$$
\widehat{\Pi}_{i 0}(k)=\max \sum_{t=0}^{\infty} \beta^{t} E_{0} \mu_{t}\left\{c_{i t}(k)\left[p_{i t}(k)-\frac{w_{t}}{z_{i t}}\right]\right\}
$$

subject to (3.8) and (3.11), the linear production function $c_{i t}(k) \leq z_{i t} l_{i t}(k)$ and the 
initial condition $M_{i 0}(k)=1$. $\frac{w_{t}}{z_{i t}}$ corresponds to the marginal cost at time $t$. The firm discounts profits using the marginal value of a dollar to the households (and owners), $\mu_{t}$, which varies over time in the general equilibrium version of the model. ${ }^{15}$

When the firm is setting its price, $p_{i t}(k)$, it takes into account four effects. First, the firm considers the impact on profit per unit sold, i.e. $\left(p_{i t}(k)-\frac{w_{t}}{z_{i t}}\right)$; second, the effect on the intensive margin for all customers; third, the consequence on the extensive margin for repeat customers through the impact on $\widehat{\delta}_{i t}(k)$; and fourth, the indirect effect on future market share. In the case of a rise in the price relative to the other brands, the first effect is positive (raising $p_{i t}(k)$ increases per-unit profit) while all the others are negative.

Once we rewrite the problem in Lagrangean form, the first-order condition with respect to $c_{i t}(k)$ is given by:

$$
p_{i t}(k)-\frac{w_{t}}{z_{i t}}=\lambda_{i t}(k)
$$

where $\lambda_{i t}(k)$ is the Lagrange multiplier on the demand faced by the firm. Equation (3.13) simply equates the value for firm $(i, k)$ of selling one more unit of the good, $\lambda_{i t}(k)$, to the per-unit profit, $p_{i t}(k)-\frac{w_{t}}{z_{i t}}$.

The optimality condition with respect to $p_{i t}(k)$ yields

$$
c_{i t}(k)=-\lambda_{i t}(k)\left[\frac{\partial c_{i t}^{N}(k)}{\partial p_{i t}(k)}+\frac{\partial c_{i t}^{R}(k)}{\partial p_{i t}(k)}\right]-v_{i t}(k) \frac{\partial M_{i t}^{R}(k)}{\partial p_{i t}(k)}
$$

where $v_{i t}(k)$ is the Lagrange multiplier associated with the law of motion of the customer base (3.8). To gain intuition for (3.14), consider the case of an increase of one unit in the price $p_{i t}(k)$. The left-hand side gives the benefit of such action: it raises revenues by the quantity sold. The right-hand side defines the costs. First, raising the price means that demand from both new and repeat customers will fall, through the quantity consumed of each customer for both groups as well as the extensive margin for repeat customers. The last term identifies the negative impact on the mass of customers which will be available for the future: it multiplies the marginal value of one more unit of customer base, $v_{i t}(k)$, by the change in market share following the

\footnotetext{
${ }^{15}$ Technically, $\mu_{t}$ is an average of the individual $\mu_{t}^{j}$.
} 
price increase.

Finally, the derivative of the Lagrangean with respect to the market share $M_{i t}(k)$ is:

$$
\begin{aligned}
v_{i t}(k)= & \beta E_{t} \frac{\mu_{t+1}}{\mu_{t}} \lambda_{i t+1}(k)\left[\frac{\partial c_{i t+1}^{N}(k)}{\partial M_{i t}(k)}+\frac{\partial c_{i t+1}^{R}(k)}{\partial M_{i t}(k)}\right] \\
& +\beta E_{t} \frac{\mu_{t+1}}{\mu_{t}} v_{i t+1}(k)\left[\frac{\partial M_{i t+1}^{N}(k)}{\partial M_{i t}(k)}+\frac{\partial M_{i t+1}^{R}(k)}{\partial M_{i t}(k)}\right] .
\end{aligned}
$$

Equation (3.15) describes the composition of the marginal value of the market share, which is purely forward-looking. ${ }^{16}$ First, raising the customer base increases sales tomorrow by having a larger mass of repeat customers as well as attracting more new consumers (since the firm is now larger). Both effects are evaluated by the marginal value to the firm of selling one more unit, $\lambda_{i t+1}(k)$. Second, it boosts the mass of customers available in the future, which has an expected value of $v_{i t+1}(k)$. On the basis of these first-order conditions, it becomes clear that it is the dynamic nature of the market share, through the presence of $v_{i t}(k)$, which renders the firm's problem intertemporal.

\subsection{Reaction of the extensive margin}

We still need an expression for the impact of the pricing decision on the extensive margin of repeat customers. Consider for example this term from equation (3.14):

$$
\frac{\partial M_{i t}^{R}(k)}{\partial p_{i t}(k)}=-M_{i t-1}(k) f\left(\widehat{\delta}_{i t}(k)\right) \frac{\partial \widehat{\delta}_{i t}(k)}{\partial p_{i t}(k)}
$$

The expression $\partial \widehat{\delta}_{i t}(k) / \partial p_{i t}(k)$ determines the reaction of the threshold switching cost to price changes. $\widehat{\delta}_{i t}(k)$ is only implicitly defined by the following relation, which is a function of all future prices:

$$
V_{0}\left[\left\{p_{i}^{t}\right\}, p_{i}^{t}(k)\right]=V_{1}\left[\left\{p_{i}^{t}\right\}, \widehat{\delta}_{i t}(k)\right]
$$

\footnotetext{
${ }^{16}$ Today's market share, $M_{i t}(k)$, does not enter the demand schedule at time $t$. Instead, it only affects the firm's problem because it corresponds to the mass of customers which the firm will start with at $t+1$.
} 
This setup exhibits a time-consistency problem: customers will be less inclined to switch away from home seller $k$ if it promises to charge low prices in the future. Hence, firms have an incentive at time $t$ to announce low future prices, but later renege on their promises. To deal with this problem, we assume that firms cannot commit to future prices. Instead, all agents in the model form expectations about $p_{i}^{t+1}(k)$ by solving firm $k$ 's problem sequentially.

The problem is further complicated by another issue. Consider a firm $(i, k)$ which raises its relative price at time $t$. Through its action, the seller will affect the customer base in the future. As the state of the firm at $t+1$ has changed, it should impact consumers' expectations about future prices. This, in turn, has an effect on the forward-looking switching decision of customers at time $t$. In other words, the object $\partial \widehat{\delta}_{i t}(k) / \partial p_{i t}(k)$ affects the firm's pricing decision, and vice-versa.

A characteristic of our model allows us to circumvent this challenge. To see this, first rewrite the firm's problem in recursive form. The Bellman equation is given by:

$$
V(M, \Omega)=\max _{p} c\left[p-\frac{w}{z}\right]+\beta E V\left(M^{\prime}, \Omega^{\prime}\right)
$$

where $M$ is the beginning-of-period mass of customers and $\Omega$ a vector of other state variables; $c, p, w / z$ are consumption, price and marginal cost respectively. Equations (3.9) and (3.10) imply that the demand schedule faced by the firm is proportional to $M$ :

$$
c=c^{R}+c^{N}=M G(p, \Omega)
$$

where $G(p, \Omega)$ is not a function of the mass of customers. Similarly, we can express the law of motion of the market share as

$$
M^{\prime}=M^{R \prime}+M^{N^{\prime}}=M H(p, \Omega)
$$

where the proportionality follows from equation (3.8). Plugging into (3.17), we obtain

$$
V(M, \Omega)=\max _{p}\left\{M G(p, \Omega)\left[p-\frac{w}{z}\right]+\beta E V\left[M H(p, \Omega), \Omega^{\prime}\right]\right\}
$$

It is then easy to show that (3.18) is linear homogenous in $M$, which allows us to 
write

$$
V(M, \Omega)=M\left\{\max _{p} G(p, \Omega)\left[p-\frac{w}{z}\right]+\beta E V\left[H(p, \Omega), \Omega^{\prime}\right]\right\} .
$$

Clearly, the initial size of the customer base only acts as a scale factor and has no impact on the pricing decision of the firm. This is a crucial finding: it implies that if a seller changes its price at time $t$, it will not affect customers' expectations about future prices, even if the market share is perturbed. ${ }^{17}$ Formally, from the point of view of any consumer $j$ we now know that:

$$
\frac{\partial E_{t}^{j} p_{i t+s}(k)}{\partial p_{i t}(k)}=0, \forall s \geq 1
$$

This result allows us to find the derivative of the threshold switching cost with respect to price from (3.16) by applying the implicit function theorem. We refer the reader to Appendix A for the details and note that the object of interest is given by:

$$
\frac{\partial \widehat{\delta}_{i t}(k)}{\partial p_{i t}(k)}=\left(\widehat{\delta}_{i t}(k)\right)^{\gamma}\left[\int_{0}^{1} M_{i t-1}(l)\left(\frac{p_{i t}(k)}{p_{i t}(l)}\right)^{\gamma} p_{i t}(l) d l\right]^{-1}
$$

\subsection{Equilibrium and steady state}

Since our focus will be on sector-specific shocks, we consider a symmetric equilibrium where all firms within each sector start in the first period with equal mass of customers $M_{i,-1}(k)=1$ and set the same price $p_{i t}(k)=p_{i t} \forall k, t$. This implies that $M_{i t}(k)=1$, $c_{i t}(k)=c_{i t}, \nu_{i t}(k)=\nu_{i t}$ and $\lambda_{i t}(k)=\lambda_{i t}$ for all $k, t$. Households are not perfectly identical in equilibrium: for a particular good, some switch at time $t$ while others stay with their home seller. However, the relevant aggregate variables $\tilde{p}_{t}^{j}, \tilde{c}_{t}^{j}$ and $\mu_{t}^{j}$ are not household-specific anymore, even if we do not impose symmetry across sectors. ${ }^{18}$ We can also show that under symmetry:

$$
c_{i t}=A(1)\left(\frac{p_{i t}}{\tilde{p}_{t}}\right)^{-\gamma} \tilde{c}_{t}
$$

\footnotetext{
${ }^{17}$ In other words, this property allows us to focus on Markov perfect equilibria where the firm's pricing decision is not a function of its past actions.

${ }^{18}$ This result is proved in an appendix available upon request.
} 
where

$$
A(1)=1-F(1)+\int_{\underline{\delta}}^{1} \delta^{1-\gamma} d F(\delta)
$$

and the first-order conditions become

$$
\begin{gathered}
\lambda_{i t}=p_{i t}-\frac{w_{t}}{z_{i t}} \\
c_{i t}=\lambda_{i t} \gamma A(1)\left(\frac{p_{i t}}{\tilde{p}_{t}}\right)^{-\gamma-1} \frac{\tilde{c}_{t}}{\tilde{p}_{t}}+\lambda_{i t} \frac{1}{p_{i t}} f(1)\left(\frac{p_{i t}}{\tilde{p}_{t}}\right)^{-\gamma} \tilde{c}_{t}+v_{i t} f(1) \frac{1}{p_{i t}} \\
v_{i t}=\beta E_{t} \frac{\mu_{t+1}}{\mu_{t}} \lambda_{i t+1} A(1)\left(\frac{p_{i t+1}}{\tilde{p}_{t+1}}\right)^{-\gamma} \tilde{c}_{t+1}+\beta E_{t} \frac{\mu_{t+1}}{\mu_{t}} v_{i t+1} .
\end{gathered}
$$

As a side note, the short-run elasticity of the demand for a single producer around the symmetric equilibrium is given by

$$
\left.\epsilon_{c_{i t}(k), p_{i t}(k)}\right|_{\frac{p_{i t}(k)}{p_{i t}}=1}=\gamma+\frac{f(1)}{A(1)} .
$$

In this framework the elasticity faced by a particular seller is greater than in the Dixit-Stiglitz case, where it simply equals $\gamma: f(1)$ represents the marginal movement in the extensive margin due to the price change, and it is deflated by the size of the taste-adjusted mass of customers. One can also show that a firm which charges $p_{i t}(k)>p_{i t}$, permanently, will eventually see its market share vanish. Therefore, the long-run elasticity faced by the firm is infinite, i.e. for any $p_{i t}(k)=p_{i t}+\varepsilon$ where $\varepsilon>0$, we have that $\lim _{t \rightarrow \infty} c_{i t}(k)=0$. 
The steady state values of the control variables are:

$$
\begin{gathered}
p_{i}=\frac{w}{z_{i}}\left[\gamma+\frac{f(1)}{A(1)}+\frac{\beta f(1)}{1-\beta}\right]\left[\gamma+\frac{f(1)}{A(1)}+\frac{\beta f(1)}{1-\beta}-1\right]^{-1} \\
\lambda_{i}=p_{i}-\frac{w}{z_{i}} \\
c_{i}=A(1)\left(\frac{p_{i}}{\tilde{p}}\right)^{-\gamma} \tilde{c} \\
v_{i}=\frac{\beta}{1-\beta} \lambda_{i} c_{i}
\end{gathered}
$$

Despite the fact that the long-run elasticity is infinite, the steady state gross markup is larger than one. This is because firms discount future profits by $\beta<1$, which means that in the limit they put no weight on the possibility that sales will eventually vanish. However, it is clear that the markup goes to 1 as $\beta \rightarrow 1$. In most

parameterizations, we find that the steady state markup is indeed very small because of the competition from other sellers of the same good.

\section{Analytics under the static case}

As is typically the case with this type of forward-looking model, we cannot derive closed-form solutions for the various endogenous variables. An exception is when the firm's problem is static: when $\beta=0$ firms do not care about the future, and hence only consider the impact of their pricing decisions on the current period's mass of customers and their level of consumption. This can be seen directly from (3.22), which implies that $v_{i t}=0$ when $\beta=0$ and thus breaks the intertemporal aspect of the firm's problem. As we later argue that it is the dynamic elements that arise from our model which deliver the important results, we first show that if the firm's problem is static, the equilibrium is indeed one where the standard predictions of the Dixit-Stiglitz model hold.

Since $v_{i t}=0$, we can express the price $p_{i t}$ as only a function of some parameters 
and the current marginal cost $m c_{i t}=\frac{w_{t}}{z_{i t}}$ :

$$
p_{i t}=\left(\frac{\gamma A(1)+f(1)}{(\gamma-1) A(1)+f(1)}\right) m c_{i t} .
$$

The assumptions about the distribution of the switching cost, $\delta$, have an impact on the level of the markup. In the special case where the distribution is such that $A(1)=1$ and $f(1)=0$, the markup is simply equal to $\frac{\gamma}{(\gamma-1)}$, similar to the DixitStiglitz case.

Most importantly, (4.1) implies that the cost pass-through is complete in the static version of our model: a rise of $5 \%$ in the marginal cost will translate into a $5 \%$ increase in prices. This is similar to the result in a standard Dixit-Stiglitz framework. One can also prove that such a strategy is the unique symmetric equilibrium, that is independent of our parameterization, and in particular holds for any distribution of $\delta$.

\section{$5 \quad$ Pricing when customer base matters}

In this section we solve for the equilibrium prices and quantities and discuss the properties of the model.

\subsection{Sectoral shocks and pricing}

We focus our attention on a setting where a sector $i$ is hit by idiosyncratic productivity shocks, common to all the firms within that sector, and study the pricing behavior of a typical seller $k$. The atomistic nature of sector $i$ implies that the aggregate consumption and price levels, $\tilde{c}_{t}$ and $\tilde{p}_{t}$, the marginal utility, $\mu_{t}$, as well as the wage rate, $w_{t}$, are all time-invariant, and we therefore drop their time subscripts. ${ }^{19}$ The law of motion of sectoral productivity is given by:

$$
\ln \left(z_{i t}\right)=\rho_{z} \ln \left(z_{i t-1}\right)+\varepsilon_{i t}^{z}
$$

\footnotetext{
${ }^{19}$ The values chosen for those variables do not affect the results in this section.
} 
where $\varepsilon_{i t}^{z}$ is a shock specific to sector $i$. We need to solve for $p_{i t}, c_{i t}, \lambda_{i t}$, and $\nu_{i t}$.

For our benchmark parameterization we pick values which are comparable to those found in the literature and later show the impact of each of them on our results. We set $\beta=0.99$ and $\gamma=5$, which is in line with the parameters estimated by Christiano, Eichenbaum and Evans (2005) for a quarterly model of the U.S. economy. We have no strong prior on the distribution of $\delta$; the evidence on switching costs is generally limited to very specific industries, and it is unclear how these estimates could be directly linked to our framework. In our benchmark, we assume that the switching $\operatorname{cost} \delta$ is distributed lognormally, with support over the interval $(0, \infty)$, mean $\mu_{\ln \delta}=$ 0.15 (or $\mu_{\delta} \approx 1.16$, so that on average switching implies a utility reduction of $16 \%$ ) and variance $\sigma_{\ln \delta}=0.1$. This parameterization implies that in equilibrium about $7 \%$ of customers in a particular sector will want to switch supplier in a given period $(F(1) \simeq 0.07)$ and that the expected duration of a match is about 3 years. The role of the distributional assumptions is carefully analyzed in a later section. We use Dynare to solve the model by linearization techniques and compute the impulse responses. We start by considering a negative productivity shock which raises the marginal cost of all producers in sector $i, \frac{w}{z_{i t}}$, by $1 \%$ in the first period. As a benchmark, we consider i.i.d. fluctuations in the marginal cost by setting $\rho_{z}=0$.

As is well known, in a standard Dixit-Stiglitz model such shocks imply a reaction of the price of good $i, p_{i t}$, perfectly proportional to the movement in marginal cost. In other words, the markup remains constant. As we show in Section 4, this is also true in the static version of our model. However, Figure 5.1 makes it clear that the addition of intertemporal market share considerations to the standard model breaks this onefor-one relationship between prices and marginal cost (unless otherwise stated, the values on the y-axis correspond to percentage deviations from steady state).

In response to a $1 \%$ increase in their marginal cost in period 1 , firms decide to raise their prices in order to mitigate the negative impact on their profit margin. However, unlike the Dixit-Stiglitz case, the pass-through of marginal cost to price is only about $60 \%$. Hence, in an environment where sectors or industries are hit by idiosyncratic marginal cost shocks, our model yields price rigidity and a time-varying markup. Since the price of good $i$ rises relative to the price of other goods, $c_{i t}$ falls as expected. In Appendix B, we confirm analytically that full pass-through cannot 

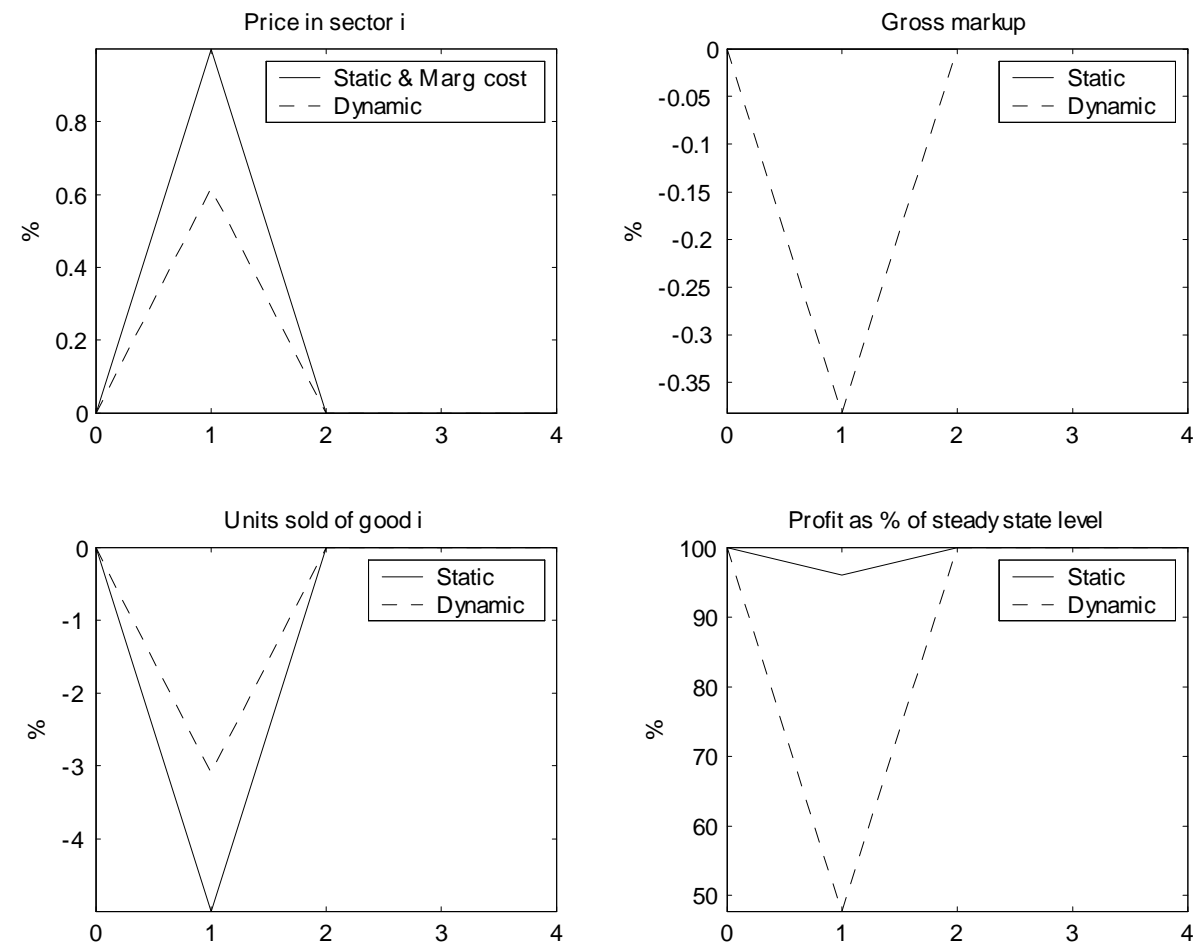

Figure 5.1: Response to a $1 \%$ increase in the marginal cost of sector $i$

be an equilibrium in this environment. ${ }^{20}$

Profits, which are small in steady state, are heavily affected by the reduction in markup. ${ }^{21}$ In fact, an interesting implication of our model is that firms may willingly and optimally decide to sustain instantaneous negative profits for a certain period of time in order to preserve their market share, without having any incentive to exit. This happens because in our environment, exiting in a single period has severe consequences for the future: it implies that firms lose a customer base which will later be difficult to rebuild. ${ }^{22}$ It clearly discourages sellers from shutting down operations

\footnotetext{
${ }^{20}$ Ravn, Schmitt-Grohé and Uribe (2007) find comparable results. They use a model where the household's utility is a function of the aggregate level of consumption of a particular good.

${ }^{21}$ Small steady-state profits are due to the low markup and the fact that we focus on a technology with constant returns to scale. Allowing for decreasing returns would raise the level of profits and make the response in Figure 5.1 look less pronounced.

${ }^{22}$ In fact, under our assumption that the mass of switchers in a particular period is distributed across sellers in proportion to their market share, firms could never regain back their customer base
} 
temporarily, a feature which we believe is realistic and desirable.

To better understand why we obtain a time-varying markup in our model, we first define a new variable which corresponds to the marginal value of the extensive margin (or of an extra customer) at time $t$ :

$$
\bar{v}_{i t}=\lambda_{i t}\left(\frac{p_{i t}}{\tilde{p}}\right)^{-\gamma} \tilde{c}+v_{i t} .
$$

The second term on the right-hand side corresponds to the forward-looking value of the customer base from (3.15). In addition, repeat customers lead to additional sales at time $t$, an effect captured by the first term in (5.1). In Appendix C, we show that under our benchmark parameterization we can derive the following approximate relation

$$
\widehat{m k}_{i t} \approx-\frac{\bar{v}_{i}}{m k_{i}}\left[\beta E_{t} \widehat{\bar{v}}_{i t+1}-\widehat{\bar{v}}_{i t}\right]
$$

where $m k_{i t}=p_{i t} / m c_{i t}$ is the gross markup and the hatted variables refer to percentage deviations from steady state. Equation (5.2) is central to the intuition behind our results: it shows that the optimal markup today is directly linked to the expected movements in the value of the extensive margin. In other words, when the marginal value of the mass of customers is relatively high in the future, we expect the firm to lower its markup.

The impulse responses in Figure 5.2 confirm this analytical relation. The solid lines reproduce the reaction of the markup and our new variable, $\bar{v}_{i t}$, to the shock described earlier (an increase in the sectoral marginal cost of $1 \%$ in period 1 ). When facing a rise in marginal cost, the firm realizes that maintaining its profit margin requires raising the price proportionately. However, a higher price means that each customer now consumes less of the good at the intensive margin, and the value of the marginal customer, $\bar{v}_{i t}$, is consequently diminished. As the shock is transitory, the seller expects the environment to go back to steady state and the value of the customer base to rise in later periods. For a firm facing a dynamic problem, this in turn affects its pricing decision: it now becomes optimal for the seller to absorb today

after exiting. But even under less extreme environments, the market share dynamics would create a strong disincentive to exit the market only for a few periods. Also, the same rationale explains why there is no incentive for outsider firms to enter the market. 

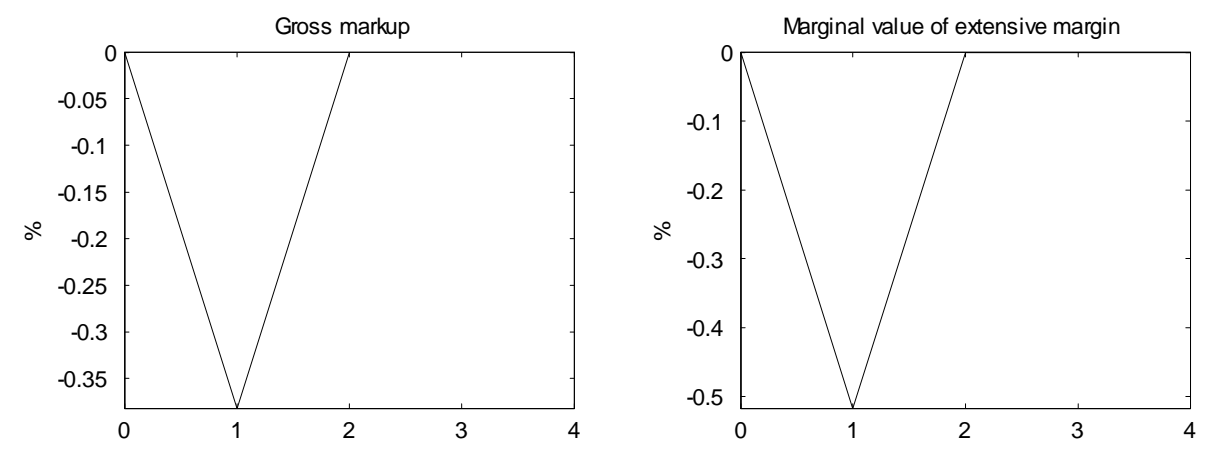

Figure 5.2: Markup and marginal value of extensive margin

a portion of the rising marginal cost into its markup in order to attract customers who are expected to be more valuable in the future. This mechanism results in price fluctuations which are muted relative to the standard Dixit-Stiglitz model.

The intuition for the case of a fall in the marginal cost is simply reversed: there, firms would have an incentive to raise their markup today since customers are not as valuable in the future. This result is related to Klemperer's (1995) observation that in an environment with switching costs, firms will most likely respond to positive demand conditions by raising prices because they "prefer to take profits in the current period rather than in the relatively less attractive future." In our simulations, demand conditions are endogenously changing through the intensive margin following price fluctuations.

Based on the intuition behind the benchmark results, one might expect that firms would react differently based on their expectations about the persistence of the marginal cost shock. Figure 5.3 confirms this conjecture: as the persistence of the shock decreases, the relative price in sector $i$ becomes more rigid. To understand why pass-through is complete when $\rho_{z}=1$, recall equation (5.2): because the change in marginal cost is permanent, the marginal value of the extensive margin is lower not only today but also in all future periods. Consequently, the intertemporal substitution motive of the firm is irrelevant: with customers having a permanently lower value, the seller has no incentive to deviate from the full pass-through equilibrium to invest in its market share. However, as the shock becomes more temporary, the firm 
is less and less willing to maintain its profit margin intact because this would imply losing a customer base which will become valuable again very soon.
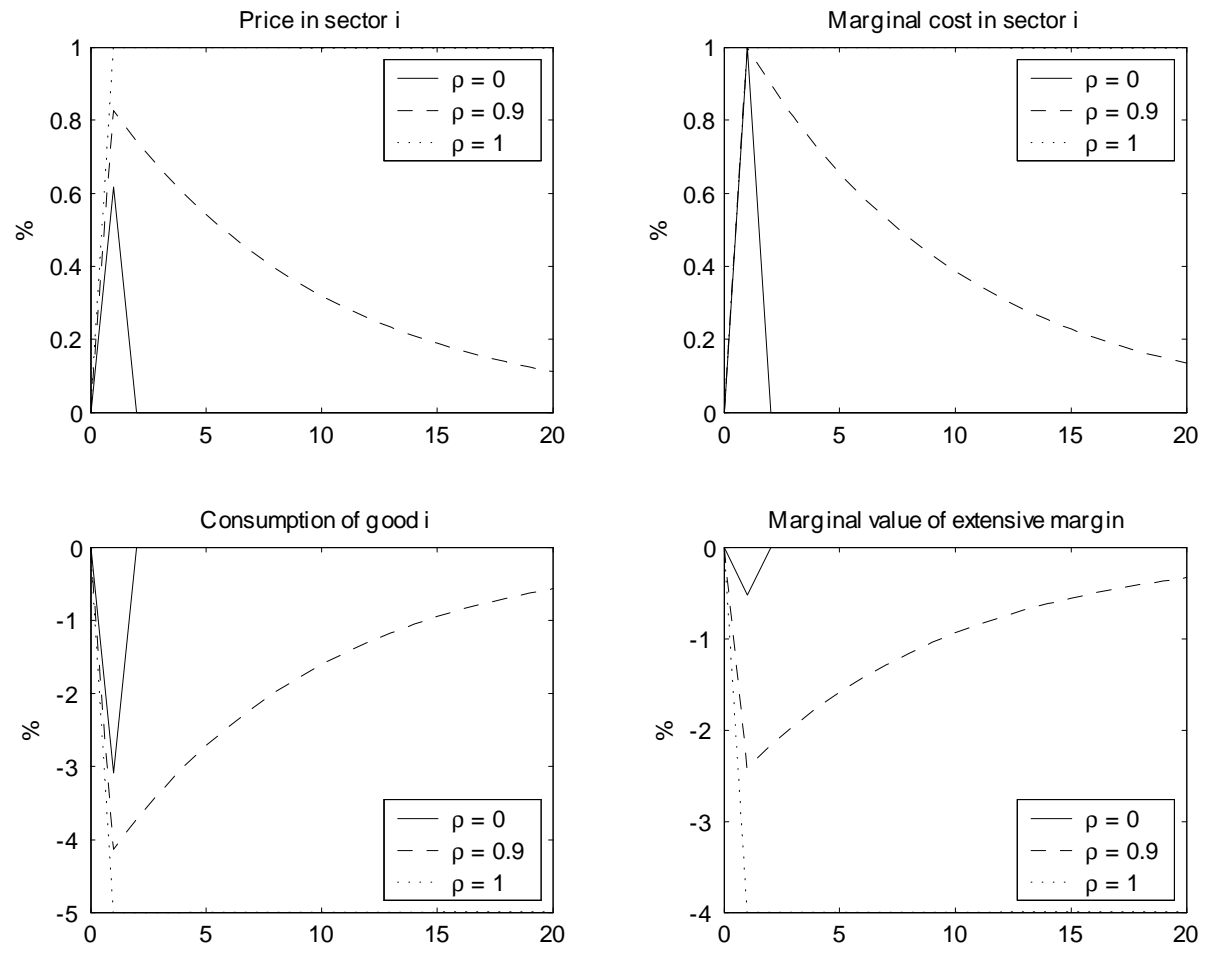

Figure 5.3: Dynamic response and persistence of the shock

In Appendix D, we analyze the firm's optimal decision when it is uncertain about the persistence of the current shock. We show that in an environment where temporary sector-specific shocks are predominant, sellers will initially respond to a change in their marginal cost by only partially raising prices, and slowly revise their strategy as they update their priors. This learning mechanism naturally leads to a delayed response of prices to persistent shocks.

\subsection{Scope of the shock and cost pass-through}

So far, we have focused on the response of prices to sector-specific marginal cost shocks. Under symmetry, all sellers of the same good behave similarly in equilibrium, and there is no price dispersion at the sectoral level. 
Arguably, disturbances may also be firm-specific in nature. The complication in this case arises from the fact that we do not have a closed-form expression for the threshold switching cost $\widehat{\delta}_{i t}(k)$, which will not be equal to 1 anymore as under the symmetric equilibrium. However, there is a special case for which we can solve for the optimal response: a temporary $\left(\rho_{z}=0\right)$ shock to the marginal cost of seller $k$ around the symmetric equilibrium where all current and future prices within sector $i$ are the same. Since we know that a price change by seller $k$ does not affect agents' expectations of its future prices, the continuation values of $V_{0}$ and $V_{1}$ remain equal and we can solve for the threshold switching cost:

$$
\widehat{\delta}_{i t}(k)=\frac{p_{i t}(k)}{p_{i t}} .
$$

This allows us to simulate the model, using the first-order conditions, (3.13)(3.15), and the expression for the derivative of the threshold switching cost, (3.19). Unlike the symmetric case, the model here is not stationary: our assumption that the arrival rate of new customers is proportional to the size of the firm implies that the market share, $M_{i t}(k)$, and the consumption level, $c_{i t}(k)$, do not go back to their initial levels following a temporary shock. Accordingly, we rescale the model by dividing the equilibrium conditions by $M_{i t-1}(k)$ and define the variables $\breve{c}_{i t}(k)=c_{i t}(k) / M_{i t-1}(k)$ and $\breve{M}_{i t}(k)=M_{i t}(k) / M_{i t-1}(k)$.

Figure 5.4 plots the response of a single seller to a $1 \%$ increase in its marginal cost, around the symmetric equilibrium. The atomistic nature of the seller implies that the sector- and aggregate-level variables are not affected by the shock. We also reproduce the sector-specific case for comparison purposes.

Under the firm-specific shock, the degree of price rigidity is much higher: the seller passes-through only $24 \%$ of the rise in the marginal cost in its price, compared to $62 \%$ when the entire sector is hit. In the model, a temporary rise in the price results in a permanent fall in both the mass of customers and the demand. However, because the price change is so muted, the responses remain small: consumption falls by $1.5 \%$ in the period of the shock, and settles around $0.3 \%$ below its initial level.

Our finding is intuitive and sensible: when a seller is the only one hit by a rise in its marginal cost, it knows that its direct competitors have no incentive to raise their 

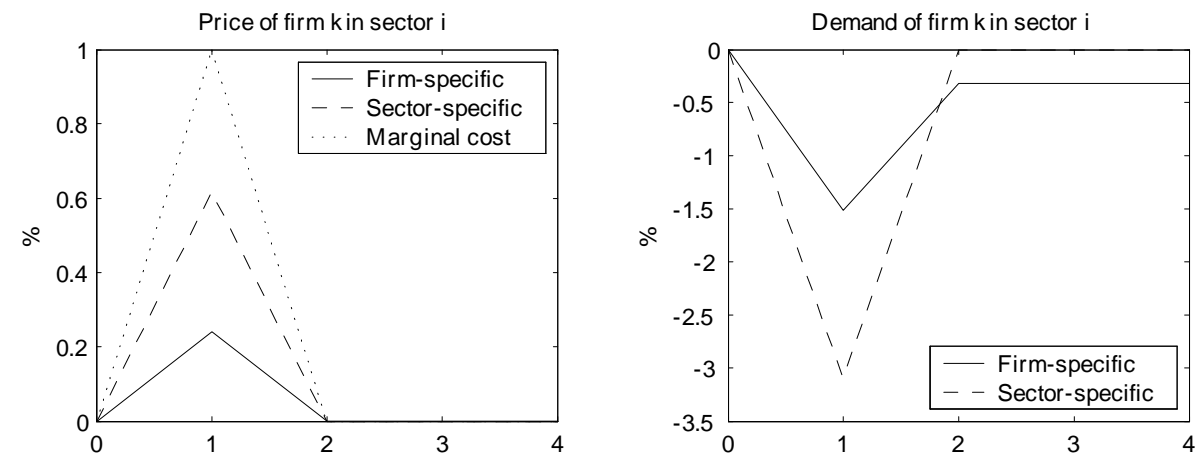

Figure 5.4: Firm- and sector-specific marginal cost shocks

prices. Therefore, the firm is particularly wary of increasing its own price, for fear of losing a portion of its market share and future profits. Gron and Swenson (2000) find that this prediction holds in the context of the U.S. automobile market: they report that "measured pass-through is higher for cost shocks experienced by all products than for model-specific shocks".

It is important to clarify that the rigidity under firm-specific shocks is not only a consequence of the dynamic nature of the firms's problem, unlike the sector-specific case. Here, the real rigidity is both intratemporal and intertemporal: the fluctuation in $\widehat{\delta}_{i t}(k)$ in itself discourages the firm from passing-through completely the rise in the marginal cost, even if it does not care about the future. However, it remains true that customer base dynamics significantly amplify the rigidity of prices: when $\beta=0$, the pass-through rises from $24 \%$ to $61 \%$.

The incomplete marginal cost pass-through in the case of sector-specific shocks stems from intertemporal fluctuations in the value of the customer base coming from the intensive margin. What we find throughout our simulations is that as goods become better substitutes, that is as $\gamma$ increases, firms become more reluctant to raise prices. This is because when goods are more substituable, an increase in the sectoral price relative to the aggregate price level results in a larger drop in the quantity consumed by each customer. In turn, the response of the value of the extensive margin is exacerbated, leading to a stronger response of the markup and a more muted price response. 
The same rationale explains why our mechanism cannot in itself generate price rigidity in the wake of aggregate shocks. If all sectors are hit at the exact same time and firms have full information, then they will fully pass-through marginal changes into their prices. ${ }^{23}$ This is in fact a standard result for models based on real rigidities. To obtain price stickiness following a monetary expansion, one would need to interact our mechanism with nominal rigidities or make firms uncertain about the scope of the shock, an exercise which we do not pursue here. ${ }^{24}$

\subsection{Switching costs and price rigidity}

We present evidence in Section 2 that not only do firms point to customer-related factors as the main reason for keeping prices stable, but those concerns appear to be correlated with the degree of price rigidity. In our model, customer base dynamics arise because households face some costs of switching suppliers. Next, we describe how the marginal cost pass-through is affected by the distribution of the switching $\operatorname{costs} \delta$, and how this relates to the empirical evidence presented in Section 2. We focus on sector-specific shocks, but the results are qualitatively similar in the firm-specific case studied in the previous section.

The distributional assumptions impact the first-order conditions (3.20)-(3.22) in two ways: through the probability density function at the equilibrium relative price of $1, f(1)$, and the taste-adjusted demand parameter $A(1)$. The latter plays only a very marginal role, and we do not discuss it further. It is easy to show from the law of motion of the market share (3.8) that the object $f(1)$ corresponds to the price elasticity of the customer base in equilibrium. As such, a change in the distribution of the switching costs will modify the model properties as long as it affects the value of $f(1)$.

To investigate the relation between price rigidity and switching costs, we simulate

\footnotetext{
${ }^{23}$ In reality, under certain parameterizations the markup can be time-varying due to some general equilibrium effects, but we find the fluctuations to be very small. The properties under economy-wide shocks are briefly discussed in Appendix B.

${ }^{24}$ The main objective of Ball and Romer (1990) was to study that interaction. They found that real rigidities could amplify the stickiness from mechanisms relying on nominal rigidities, such as menu costs. This would also be true in our setup, with an additional effect coming from the intertemporal dimension. For a recent treatment based on the Kimball (1995) aggregator, see Klenow and Willis (2006).
} 
the price response to a sector-specific marginal cost shock $\left(\rho_{z}=0.9\right)$ under different values of $\mu_{\delta}$. A distribution mean of $\mu_{\delta}=1$ indicates that, on average, there is no penalty to switching suppliers. Figure 5.5 reports the results along a few dimensions. The first plot offers a visual description of the relationship between the three objects we are interested in: as the average switching cost $\left(\mu_{\delta}\right)$ increases, the elasticity of the customer base $(f(1))$ falls and the proportion of repeat customers $(1-F(1))$ rises. ${ }^{25}$ The upper-right plot illustrates how the degree of pass-through is affected by the average size of the switching cost, $\mu_{\delta}$, while the lower graphs describe how price rigidity depends on $f(1)$ and $1-F(1)$.

Consider an extreme case where switching costs are very high: this correponds to the rightmost distribution on the first plot. In such a scenario, the market share is inelastic $(f(1)=0)$, customers are strongly attached to their current supplier, firms' market power and markup are high, there is no one switching in equilibrium and the model reverts to the standard Dixit-Stiglitz framework without an extensive margin. Consequently, firms completely pass-through any change of the sectoral marginal cost into their prices. As switching costs decrease, the elasticity of the customer base around the equilibrium rises and, not surprisingly, firms become more reluctant to pass-through cost changes. The surprising result, however, is that the relation is non-monotonic: while sector prices initially become more rigid, pass-through reaches a minimum around $\mu_{\delta}=1.3$, or a very low elasticity value of $f(1)=0.017$. After that point, and for most of the $f(1)$ parameter space, prices become more flexible as the elasticity of the market share rises. Notice that we are not considering extreme market share elasticities: in Figure 5.5, the fall in the mass of customers following a $1 \%$ rise in the relative price does not exceed $4 \%$.

Our findings indicate that, somewhat paradoxically, firms are generally more willing to pass-through marginal cost fluctuations when their customer base is very sensitive to variations in the relative price. The reason behind this result is in fact intuitive. When the market share is highly elastic, customers are not loyal and can easily switch to other suppliers. This translates into low market power for the firm

\footnotetext{
${ }^{25}$ The link between $\mu_{\delta} f(1)$, and $F(1)$ is clear under a unimodal distribution for the switching costs such as the lognormal distribution we use here. However, the intuition is not obvious under bimodal distributions, for example. Similarly, the case where switching costs are uniformly distributed would be uninteresting, given that $f(1)$ could then take only two extreme values.
} 

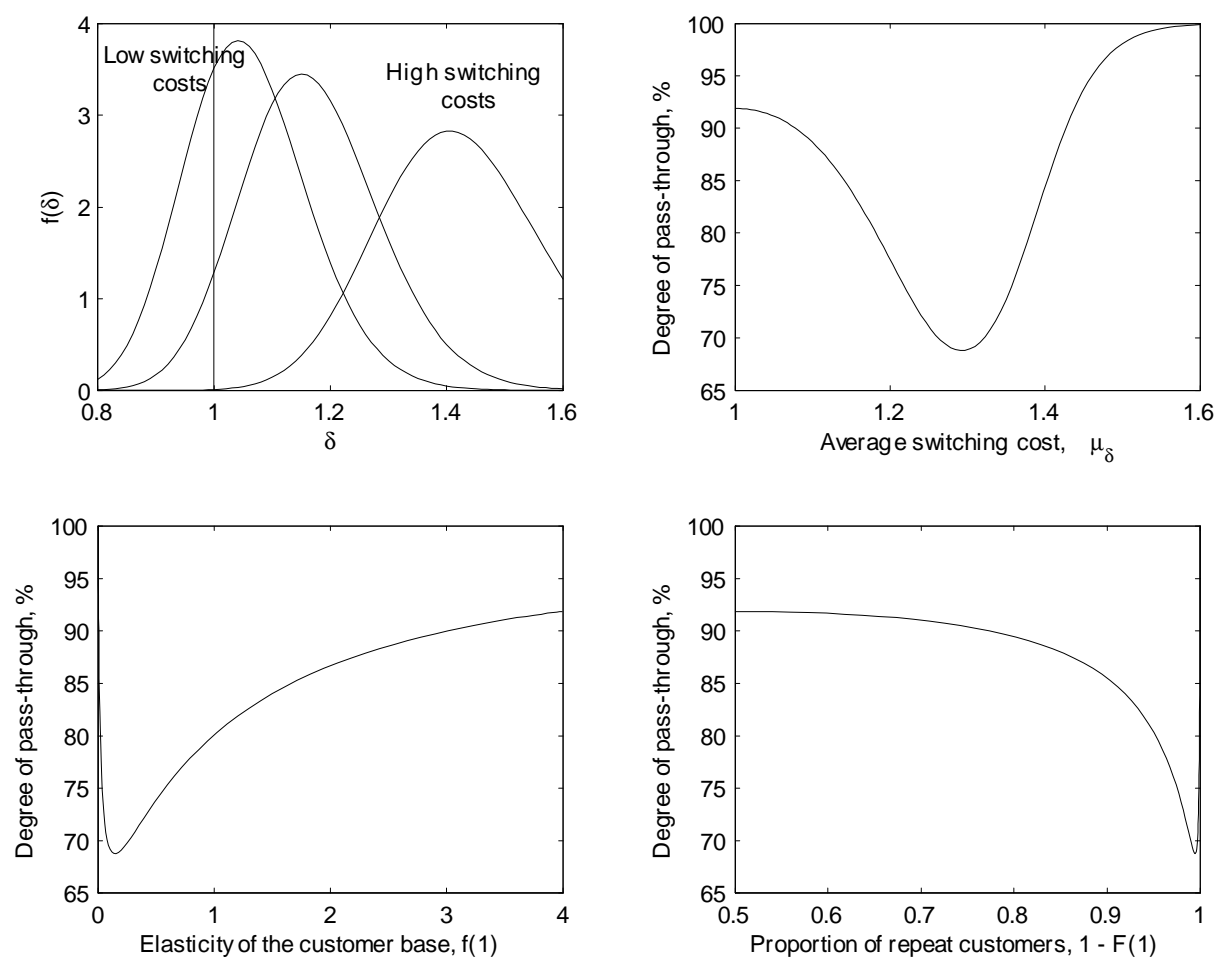

Figure 5.5: Pass-through and distribution of switching costs

and low equilibrum markups, a well-known result in the industrial organization literature (Klemperer (1995)). The customer base is therefore not valued as much by the seller, which explains the negative relation between the marginal value of the market share, $v_{i}$, and $f(1)$ (see the steady state equations (3.24)). The value of the customer base in turns interacts with the pricing decision of the firm: the seller will be less inclined to cut its profit margin to preserve its market share when the marginal value of customers is low. This is what we call the "loyalty effect", and its interaction with the "elasticity effect" determines the degree of price rigidity in the model. For very low values of $f(1)$, the elasticity effect is the most potent, while the loyalty effect quickly takes over as switching costs fall. This explains the non-monotonic relationship between switching cost and pass-through from Figure 5.5.

As an illustration, consider an industry in which individuals value highly a close and continuous business relationship with their provider and where switching is in- 
frequent, such as in the case of barbers, for example. One would expect that the customer switching costs are relatively high in such sectors, since they incorporate "costs related to the loss of capitalized value of relationships previously established" (Kim, Kliger and Vale (2001)). Klemperer (1995) also notes that "markets for professional services of doctors, consultants, accountants, etc. involve switching costs of several, and perhaps all, kinds."

On the one hand, a barber facing a rise in his marginal cost might be more inclined to capitalize on his captive clientele by raising prices: since the elasticity of the customer base is low, any price deviation is not expected to affect the market share much. However, a price increase has the potential to encourage some valuable customers to switch, with the consequence of losing a significant revenue stream for the future. In the model, this second force generally dominates, and industries with less elastic customer base have more rigid prices. Now consider the opposite case: when switching costs are on average very small, customers often switch for exogenous reasons and the expected length of a match is short. There is, therefore, little incentive for the firm to sacrifice current profits in order to preserve its market share, since there is a high probability that any customer retained will switch supplier in the near future.

We also show in Section 2 that firms with a higher fraction of repeat customers empirically tend to have more rigid prices. We find a similar link in our model: the last plot in Figure 5.5 shows that the degree of marginal cost pass-though is a decreasing function of the proportion of repeat customers, $1-F(1)$, except for extremely high values. Fabiani et al. (2005) report for a set of European countries that the average proportion of repeat customer is $70 \%$.

Interestingly, our mechanism can be linked to the notion of "customer lifetime value" or CLV, a popular concept in the recent marketing literature. According to Bauer, Hammerschmidt and Braehler (2003), "the CLV measures the profit streams of a customer across the entire customer life cycle". The authors notice that the economic reality "is marked by customer migration and a strong tendency to switch vendors" and highlight the key role of the retention rate, which "refers to the probability that an individual customer remains loyal to a particular supplier." In our model, the CLV corresponds to the value of an extra customer, $\bar{v}_{i t}$, while the retention rate 
is closely related to the elasticity of the customer base, $f(1)$, and the proportion of repeat customers, $1-F(1)$. Our contribution is to show how fluctuations in the CLV, or $\bar{v}_{i t}$, influence the firm's pricing decision.

We believe that the findings from this section can potentially explain why service prices are in general more rigid, particularly in sectors where buyer/seller relationships are important. Empirically, categories such as haircuts and beauty parlor services, legal services, home care, pet and veterinarian services, medical and dental services, etc. display the highest degree of price rigidity among all products (see Bils and Klenow (2004)).

\section{Conclusion}

We show that a standard macro model in which firms and households form long-term relationships can deliver incomplete pass-through of sector-specific cost shocks. In addition, we find that the degree of price rigidity is inversely related to the persistence of the shock, and that cost pass-through is lower in the case of firm-level disturbances. Given that firms view customer-related factors as the main impediments to having more flexible prices, we believe that our mechanism offers a sensible and interesting theory of price rigidity.

In our model, customer base dynamics arise because consumers face costs of switching to a different supplier. We show that cost pass-through is a non-monotonic function of the size of switching costs, and that prices tend to become more stable as the fraction of repeat customers increases and the elasticity of the customer base falls. Based on surveys of firms' pricing behavior, we argue that those results are in line with the empirical evidence and that they offer a potential explanation for some of the heterogeneity in price rigidity observed in the data. However, more empirical work needs to be done on the subject. As switching costs are difficult to quantify, it might prove easier to find a measure of repeated interaction between sellers and customers, and relate it to the degree of price rigidity. Additional firm surveys could also provide useful information.

Another research avenue would be to interact the real rigidity we propose with some nominal rigidities. While the evidence suggests that menu costs per se do not 
play a major role in firms' pricing decisions, it is conceivable that a small amount of menu costs coupled with the mechanism we propose could produce significant price stickiness and real effects from monetary shocks. Also, modelling firm uncertainty about the scope of the shock could be an interesting way to obtain price rigidity following aggregate shocks: if most shocks are idiosyncratic in nature, firms may be slow to recognize a shock as aggregate. Given that prices are rigid under sector- and firm-specific shocks, we conjecture that a combination of our mechanism with Lucasstyle imperfect information would give rise to real effects from monetary shocks.

A natural application of our model is in the context of international economics: in markets where both domestic and foreign firms compete, movements in the real exchange rate create a wedge between their marginal costs expressed in a common currency. In our framework, exporters would find it optimal to pass-through only a fraction of exchange rate fluctuations in order to stabilize their market share. ${ }^{26}$ This prediction is supported by the large empirical literature on exchange rate passthrough.

\footnotetext{
${ }^{26}$ In fact, our model can be interpreted as a general equilibrium version of the mechanism discussed by Froot and Klemperer (1989) in the context of exchange rate pass-through.
} 


\section{References}

Altig, D., Christiano, L.J., Eichenbaum, M. and J. Linde, 2005, "Firm-Specific Capital, Nominal Rigidities, and the Business Cycle", NBER Working Paper 11034.

Amano, R. and Hendry, S., 2003, "Inflation Persistence and Costly Market Share Adjustment: A Preliminary Analysis", BIS Papers No.19, 2003.

Apel, M., R. Friberg and K. Hallsten, 2005, "Microfoundations of Macroeconomic Price Adjustment: Survey Evidence from Swedish Firms", Journal of Money, Credit and Banking, Vol. 37, No. 2, 314-338.

Amirault, D., Kwan, C., and G. Wilkinson, 2006, "Survey of Price-Setting Behaviour of Canadian Companies", Bank of Canada Working Paper 2006-35.

Aucremanne, L. and M. Druant, 2005, "Price-Setting Behaviour in Belgium: What Can Be Learned from an Ad-Hoc Survey?", ECB Working Paper No. 448.

Baudry, L., Le Bihan, H., Sevestre, P. and S. Tarrieu, 2004, "Price Rigidity: Evidence from the French CPI Micro-Data", ECB Working Paper No. 384.

Bauer, H. H., Hammerschmidt, M. and M. Braehler, 2004, "The Customer Lifetime Value Concept and Its Contribution to Corporate Valuation," Yearbook of Marketing and Consumer Research, Vol. 1, Berlin: Duncker \& Humblot, 47-67.

Ball, L. and D. Romer, 1990, "Real Rigidities and the Non-Neutrality of Money," The Review of Economic Studies, Vol. 57, No. 2, 183-203.

Besanko, D., Dubé, J.-P., and S. Gupta, 2005, "Own-Brand and Cross-Brand Retail Pass-Through," Marketing Science, Vol.24, No. 1, 123-137.

Bils, M., 1987, "The Cyclical Behavior of Marginal Cost and Price", American Economic Review, Vol. 77, No 5, 838-855.

Bils, M. and P. Klenow, 2004, "Some Evidence on the Importance of Sticky Prices", Journal of Political Economy, Vol. 112, No 5, 947-985. 
Blinder, A.S., E.R.D. Canetti, D.E. Lebow and J.B. Rudd, 1998, Asking about Prices: A New Approach to Understanding Price Stickiness, New York: Russell Sage.

Borenstein, S., Cameron, A.C., R. Gilbert, 1992, "Do Gasoline Prices Respond Asymmetrically to Crude Oil Price Changes?", NBER Working Paper 4138.

Burstein, A., Eichenbaum, M., and S. Rebelo, 2005, "Large Devaluations and the Real Exchange Rate", Journal of Political Economy, Vol.113, No.4, 742-784.

Cason, T.N. and D. Friedman, 2002, "A Laboratory Study of Customer Markets," Advances in Economic Analysis and Policy, Vol.2, Issue 1.

Campa, J.M. and L.S. Goldberg, 2002, "Exchange Rate Pass-Through into Import Prices: a Macro or Micro Phenomenon?," NBER Working Paper 8934.

Christiano, L., Eichenbaum, M. and C. Evans, 2005, "Nominal Rigidities and the Dynamic Effects of a Shock to Monetary Policy", Journal of Political Economy, February, 2005, 113 (1), 1 -45.

Dhyne, E., Alvarez, L.J., Le Bihan, H., Veronese, G., Dias, D., Hoffman, J., Jonker, N., Lünnemann, P., Rumler, F. and J. Vilmunen, 2005, "Price-Setting in the Euro Area: some Stylized Facts from Individual Consumer Price Data", ECB Working Paper No. 524.

Dixit, A.K. and J.E. Stiglitz, 1977, "Monopolistic Competition and Optimum Product Diversity", American Economic Review, 67, 297-308.

Dotsey, M. and R. King, 2005, "Implications of State-Dependent Pricing for Dynamic Macroeconomic Models," Journal of Monetary Economics, 52(1), 213-242.

Fabiani, S., Druant, M., Hernando, I., Kwapil, C., Landau, B., Loupias, C., Martins, F., Matha, T.Y., Sabbatini, R., Stahl, H. and A.C.J. Stockman, 2005, "The Pricing Behaviour of Firms in the Euro Area", ECB Working Paper No. 535.

Froot, K. and P. Klemperer, 1989, "Exchage rate Pass-Through When Market Share Matters," American Economic Review 79, 637-654. 
Gagnon, E., 2006, "Price Setting during Low and High Inflation: Evidence from Mexico", mimeo Federal Reserve Board.

Ghanesh, J., M.J. Arnold and K.E. Reynolds, 2000, "Understanding the Customer Base of Service Providers: An Examination of the Differences between Switchers and Stayers", Journal of Marketing, July 2000, 64(3): 65-87.

Golosov, M. and R.E. Lucas, Jr., 2003, "Menu Costs and Phillips Curves", NBER Working Paper $1018 \%$.

Gron, A. and D.L. Swenson, 2000, "Cost Pass-through in the U.S. Automobile Market", The Review of Economics and Statistics, 82(2): 316-324.

Hall, S., Walsh, M., and A. Yates, 1997, "How Do U.K. Companies Set Prices?" Bank of England Working Paper No.67.

Ireland, P.N., 1998, "Customer Flows, Countercyclical Markups, and the Output Effects of Technology Shocks", Journal of Macroeconomics, 20(4), 649-664.

Keaveney, S.M., 1995, "Customer Switching Behavior in Service Industries: An Explanatory Study", Journal of Marketing, April 1995, 59(2): 71-82.

Kim, M., Kliger, D., and B. Vale, 2001, "Estimating Switching Costs and Oligopolistic Behavior", Wharton School for Financial Institutions Center, WP 01-13.

Klenow, P.J. and J.L. Willis, 2006, "Real Rigidities and Nominal Price Changes," Kansas City Fed, Working Paper 06-03.

Klemperer, P., 1995, "Competition when Consumers Have Switching Costs: An Overview with Applications to Industrial Organization, Macroeconomics, and International Trade", The Review of Economic Studies, 62:4, 515-539.

Kwapil, C., Baumgartner, J. and J. Scharley, 2005, "The Price-Setting Behavior of Austrian Firms: Some Survey Evidence", ECB Working Paper No. 464.

Lach, S. and D. Tsiddon, 1992, "The Behavior of Prices and Inflation: An Empirical Analysis of Disaggregated Price Data", Journal of Political Economy, 100:2. 
Nakamura, E. and J. Steinsson, 2007, "Price Setting in Forward-Looking Customer Markets", mimeo Harvard University.

Neumark, D. and S.A. Sharpe, 1992, "Market Structure and the Nature of Price Rigidity: Evidence from the Market for Consumer Deposits," The Quarterly Journal of Economics, 107:2, 657-680.

Okun, A. ,1981, Prices and Quantities: A Macroeconomic Analysis, Blackwell:Oxford.

Peltzman, S., 2000, "Prices Rise Faster than They Fall", Journal of Political Economy, 108:3, 466-502.

Phelps, E.S. and S. Winter, 1970, "Optimal Price Policy under Atomistic Competition," Microeconomic Foundations of Employment and Inflation Theory (Norton).

Ravn, M., S. Schmitt-Grohé, and M. Uribe, 2006, "Deep Habits," Review of Economic Studies 73, 2006, 195-218.

Ravn, M., S. Schmitt-Grohé, and M. Uribe, 2007,"Incomplete Cost Pass-Through Under Deep Habits," NBER Working Paper No. 12961.

Renner, E. and J.-R. Tyran, 2004, "Price Rigidity in Customer Markets", Journal of Economic Behavior \&3 Organization, Vol. 55, 575-593.

Rotemberg, J., 2005, "Customer Anger at Price Increases, Time Variation in the Frequency of Price Changes and Monetary Policy", Journal of Monetary Economics $52,829-852$.

Rotemberg, J., J., and M. Woodford , 1997, "An Optimization-Based Econometric Model for the Evaluation of Monetary Policy," NBER Macroeconomics Annual 12: $297-346$

Rotemberg, J., J., and M. Woodford, 1999, "The Cyclical Behavior of Prices and Costs," in J.B. Taylor and M. Woodford, eds., Handbook of Macroeconomics, $1 \mathrm{~B}$.

Stiglitz, J. E., 1979, "Equilibrium in Product Markets with Imperfect Information", American Economic Review, 69, 339-345. 
Wiederholt, M., and B. Mackowiak, 2006, "Optimal Sticky Prices and Rational Inattention," mimeo Northwestern University.

Woglom, G., 1982, "Underemployment Equilibrium with Rational Expectations", Quarterly Journal of Economics, 97, 89- 107.

Zbaracki, M.J., Ritson, M., Levy, D., Dutta, S., and M. Bergen, 2004, "Managerial and Customer Costs of Price Adjustment: Direct Evidence from Industrial Markets", The Review of Economics and Statistics, 86(2), 514-533. 


\section{A Switching Rule}

In this appendix we show the details behind the derivation of the object $\partial \widehat{\delta}_{i t}(k) / \partial p_{i t}(k)$. The threshold switching cost $\widehat{\delta}_{i t}(k)$ is implicitly defined by equating the value of remaining with the current supplier, $V_{0}$, to the value of switching, $V_{1}$ :

$$
V_{0}\left[\left\{p_{i}^{t}\right\}, p_{i}^{t}(k)\right]=V_{1}\left[\left\{p_{i}^{t}\right\}, \widehat{\delta}_{i t}(k)\right]
$$

Even if different threshold consumers have different aggregates $\tilde{p}_{t}^{j}$ and $\tilde{c}_{t}^{j}$ out of equilibrium, those variables do not affect the marginal decisions to stay or switch for a particular seller. Clearly, this choice is only a function of the switching cost, the price charged by the home seller and the distribution of prices from other sellers. Therefore, we focus on a typical threshold costumer and drop the $j$ subscripts to be concise.

By defining the function $G\left[\left\{p_{i}^{t}\right\}, p_{i}^{t}(k), \widehat{\delta}_{i t}(k)\right]=V_{0}-V_{1}=0$, it is easy to verify that at the symmetric equilibrium where $p_{i}^{t}(l)=p_{i}^{t}, \forall l$, we have that $\widehat{\delta}_{i t}=1$ and the following conditions are satisfied:

$$
\begin{gathered}
G\left[\left\{p_{i}^{t}\right\}, p_{i}^{t}, \widehat{\delta}_{i t}=1\right]=0 \\
\frac{\partial G}{\partial \widehat{\delta}_{i t}}\left[\left\{p_{i}^{t}\right\}, p_{i}^{t}, \widehat{\delta}_{i t}=1\right] \neq 0 .
\end{gathered}
$$

We therefore know that the implicit function theorem applies around the symmetric equilibrium, which is all we need for our purpose.

$$
\frac{\partial \widehat{\delta}_{i t}(k)}{\partial p_{i t}(k)}\left[\left\{p_{i}^{t}\right\}, p_{i}^{t}, \widehat{\delta}_{i t}=1\right]=-\frac{\frac{\partial G}{\partial p_{i t}(k)}\left[\left\{p_{i}^{t}\right\}, p_{i}^{t}, \widehat{\delta}_{i t}=1\right]}{\frac{\partial G}{\partial \widehat{\delta}_{i t}(k)}\left[\left\{p_{i}^{t}\right\}, p_{i}^{t}, \widehat{\delta}_{i t}=1\right]}
$$

$V_{0}$ depends only on $p_{i t}(k)$, and based on the result of the Section 3.3, we know that the continuation value is not a function of $p_{i t}(k)$. Denote the optimal demand of the typical threshold consumer by $c_{0 i t}$ and $c_{1 i t}$ in case he is either staying or switching, 
respectively:

$$
\begin{aligned}
\partial G / \partial p_{i t}(k) & =\frac{\partial U\left(c_{0 i t}\right)}{\partial c_{0 i t}} \frac{\partial c_{0 i t}}{\partial p_{i t}(k)} \\
& =\left(\tilde{c}_{t}\right)^{\frac{1}{\gamma}-\sigma}\left(\tilde{c}_{0 i t}\right)^{-\frac{1}{\gamma}}\left(-\frac{\gamma c_{0 i t}}{p_{i t}(k)}\right) \\
& =-\gamma \tilde{c}_{t}^{-\sigma} \frac{c_{0 i t}}{\tilde{p}_{t}}
\end{aligned}
$$

where we use our earlier result that $\left(\tilde{c}_{t}\right)^{\frac{1}{\gamma}}\left(c_{0 i t}\right)^{-\frac{1}{\gamma}}=p_{i t}(k) / \tilde{p}_{t}$. Also, only $V_{1}$ depends on $\widehat{\delta}_{i t}(k)$, and because the switching cost are i.i.d., the derivative with respect to the continuation value drops out. Hence:

$$
\begin{aligned}
\partial G / \partial \widehat{\delta}_{i t}(k) & =-\partial V_{1} / \partial \widehat{\delta}_{i t}(k) \\
& =-\int_{0}^{1}\left[\frac{\partial U\left(c_{1 i t}(l)\right)}{\partial \widehat{\delta}_{i t}(k)}+\frac{\partial U\left(c_{1 i t}(l)\right)}{\partial c_{1 i t}(l)} \frac{\partial c_{1 i t}(l)}{\partial \widehat{\delta}_{i t}(k)}\right] d l \\
& =\int_{0}^{1} \gamma\left(\tilde{c}_{t}\right)^{-\sigma} c_{1 i t}(l) \frac{1}{\widehat{\delta}_{i t}(k)} \frac{p_{i t}(l)}{\tilde{p}_{t}} d l
\end{aligned}
$$

where we use $\left(\tilde{c}_{t}\right)^{\frac{1}{\gamma}}\left(\tilde{c}_{1 i t}(l)\right)^{-\frac{1}{\gamma}} \widehat{\delta}_{i t}(k)^{\frac{1}{\gamma}-1}=p_{i t}(l) / \tilde{p}_{t}$. We know that:

$$
\frac{c_{0 i t}}{c_{1 i t}(l)}=\widehat{\delta}_{i t}(k)^{\gamma-1}\left(\frac{p_{i t}(k)}{p_{i t}(l)}\right)^{-\gamma}
$$

therefore, we obtain:

$$
\begin{aligned}
\frac{\partial \widehat{\delta}_{i t}(k)}{\partial p_{i t}(k)} & =\frac{\gamma \tilde{c}_{t}^{-\sigma} c_{0 i t}}{\int_{0}^{1} \gamma\left(\tilde{c}_{t}\right)^{-\sigma} c_{1 i t}(l) \frac{1}{\widehat{\delta}_{i t}(k)} p_{i t}(l) d l} \\
& =\widehat{\delta}_{i t}(k)\left[\int_{0}^{1} \frac{c_{1 i t}(l)}{c_{0 i t}} p_{i t}(l) d l\right]^{-1}
\end{aligned}
$$




$$
\frac{\partial \widehat{\delta}_{i t}(k)}{\partial p_{i t}(k)}=\left(\widehat{\delta}_{i t}(k)\right)^{\gamma}\left[\int_{0}^{1}\left(\frac{p_{i t}(k)}{p_{i t}(l)}\right)^{\gamma} p_{i t}(l) d l\right]^{-1}
$$

which, evaluated at the symmetric equilibrium, simplifies to:

$$
\frac{\partial \widehat{\delta}_{i t}(k)}{\partial p_{i t}(k)}\left[\left\{p_{i}^{t}\right\}, p_{i}^{t}, \widehat{\delta}_{i t}=1\right]=\frac{1}{p_{i t}}
$$

\section{B Equilibrium in a Dynamic Setting}

We now study the incentive of a seller $k$ to deviate from a symmetric equilibrium where all firms fully pass-through the marginal cost shock into their prices. Here we focus on the case of a purely transitory shock $\left(\rho_{z}=0\right)$ because it is analytically tractable.

Recall that the discounted sum of profits $\widehat{\Pi}_{i 0}(k)$ of the $(i, k)$ seller is given by (3.12). Its derivative with respect to price at $t=0$ around the symmetric equilibium is:

$$
\left.\frac{\partial \widehat{\Pi}_{i 0}(k)}{\partial p_{i 0}(k)}\right|_{\left\{\frac{p_{i t}(k)}{p_{i t}}=1\right\}}=\mu_{0} c_{i 0}+\left.\sum \beta^{t} \mu_{t} \frac{\partial c_{i t}(k)}{\partial p_{i o}(k)}\right|_{\frac{p_{i t}(k)}{p_{i t}}=1}\left[p_{i t}-m c_{i t}\right] .
$$

Since we are starting from a complete pass-through equilibrium, we denote the new exogenous marginal cost at time 0 by $m c_{i 0}=\kappa$, and the new price charged by all sellers in sector $i$ as $p_{i 0}=\kappa p_{i}$, where $p_{i}$ is the steady state value of the price. Since we use the nominal wage $w$ as the numeraire and normalize it to $1, m c_{i 0}=\kappa$ can also be interpreted as $z_{i 0}=1 / \kappa$. For $t>0$, we assume that $m c_{i t}=1$ (temporary shock), and since the model is purely forward-looking in equilibrium, it can be shown that $p_{i t}=p_{i}$, that is the model is back to steady state starting from period $t=1$.

Based on the demand function (3.11), we find that:

$$
\left.\frac{\partial c_{i 0}(k)}{\partial p_{i o}(k)}\right|_{\frac{p_{i 0}(k)}{p_{i 0}}=1}=-\left(\frac{p_{i 0}}{\tilde{p}_{0}}\right)^{-\gamma-1} \frac{\tilde{c}_{0}}{\tilde{p}_{0}}[\gamma A(1)+f(1)] .
$$

The derivative of future consumption with respect to $p_{i 0}(k)$ identifies an effect only through the extensive margin. This is because a change in price today will 
impact the market share in the future, but not the per-customer level of consumption (the intensive margin):

$$
\left.\frac{\partial c_{i t}(k)}{\partial p_{i o}(k)}\right|_{\frac{p_{i t}(k)}{p_{i t}}=1}=-\frac{f(1)}{p_{i 0}} A(1)\left(\frac{p_{i t}}{\tilde{p}_{t}}\right)^{-\gamma} \tilde{c}_{t} .
$$

Recall that $\tilde{p}=p_{i} A(1)^{\frac{1}{1-\gamma}}$, which yields

$$
\left.\frac{\partial c_{i t}(k)}{\partial p_{i o}(k)}\right|_{\frac{p_{i t}(k)}{p_{i t}}=1}=-\frac{f(1)}{p_{i 0}} A(1)^{\frac{1}{1-\gamma}} \tilde{c} .
$$

We plug this into our initial expression and use $m c_{i 0}=\kappa$ and $p_{i 0}=\kappa p_{i}$ to get:

$$
\begin{aligned}
\left.\frac{\partial \widehat{\Pi}_{i 0}(k)}{\partial p_{i 0}(k)}\right|_{\left\{\frac{p_{i t}(k)}{p_{i t}}=1\right\}}= & \left(\frac{\kappa p_{i}}{\tilde{p}_{0}}\right)^{-\gamma} \mu_{0} \tilde{c}_{0}\left[A(1)-\frac{1}{k p_{i}}[\gamma A(1)+f(1)]\left[\kappa p_{i}-\kappa\right]\right] \\
& -\sum \beta^{t} \mu_{t} \frac{f(1)}{k p_{i}} A(1)^{\frac{1}{1-\gamma}} \tilde{c}\left[p_{i}-1\right] .
\end{aligned}
$$

Next, we use the steady state expression for the price $p_{i}$ and re-arrange in order to simplify the equation:

$$
\left.\frac{\partial \widehat{\Pi}_{i 0}(k)}{\partial p_{i 0}(k)}\right|_{\left\{\frac{p_{i(t)}(k)}{p_{i t}}=1\right\}}=\left[\frac{\frac{\beta f(1) A(1)}{1-\beta}}{\gamma+\frac{\beta f(1)}{1-\beta}+\frac{f(1)}{A(1)}}\right]\left[\left(\frac{\kappa p_{i}}{\tilde{p}_{0}}\right)^{-\gamma} \frac{\tilde{c}_{0}^{1-\sigma}}{\tilde{p}_{0}}-\frac{\tilde{c}^{1-\sigma}}{\kappa p_{i} A(1)}\right],
$$

where the last line uses the definition of the aggregate price index $\tilde{p}$.

We now analyze some specific cases which we consider in the text. First, notice that if firms and households do not care about the future $(\beta=0)$, the derivative of the profit function with respect to the price around a full pass-through equilibrium is simply equal to 0 . In other words, when the agents are not forward-looking, full pass-through is a sustainable symmetric equilibrium, in line with our previous results. This is also true if $f(1)=0$, that is, if the market share is price inelastic.

Second, if the shock at $t=0$ is sector specific, the price index $\tilde{p}_{0}$ and the aggregate consumption remain constant as sectors are atomistic. By setting $\tilde{p}_{0}=p_{i} A(1)^{\frac{1}{1-\gamma}}$ and 
$\tilde{c}_{0}=\tilde{c}$ we obtain:

$$
\left.\frac{\partial \widehat{\Pi}_{i 0}(k)}{\partial p_{i 0}(k)}\right|_{\left\{\frac{p_{i t}(k)}{p_{i t}}=1\right\}}=\left[\frac{\frac{\beta f(1) A(1)}{1-\beta}}{\gamma+\frac{\beta f(1)}{1-\beta}+\frac{f(1)}{A(1)}}\right] \frac{\tilde{c}^{1-\sigma}}{\kappa p_{i} A(1)}\left[\frac{1}{\kappa^{\gamma-1}}-1\right] .
$$

In this case, there is an incentive to deviate for any non-zero shock to the marginal cost $(\kappa \neq 1)$. For example, if the marginal cost increases in period $0(\kappa>1)$, the term in the last bracket becomes negative, indicating that a seller has an incentive to deviate from the full pass-through equilibrium by lowering its price. Therefore, under the scenario of a sector-specific shock, the symmetric equilibrium will be one where firms do not fully pass-through changes in their marginal cost.

Finally, we consider the case of an economy-wide shock hitting all sectors simultaneously. We know from our previous results that the aggregate price index can be replaced by $\tilde{p}_{0}=p_{i 0} A(1)^{\frac{1}{1-\gamma}}=\kappa p_{i} A(1)^{\frac{1}{1-\gamma}}$ :

$$
\left.\frac{\partial \widehat{\Pi}_{i 0}(k)}{\partial p_{i 0}(k)}\right|_{\left\{\frac{p_{i t}(k)}{p_{i t}}=1\right\}}=\left[\frac{\frac{\beta f(1) A(1)}{1-\beta}}{\gamma+\frac{\beta f(1)}{1-\beta}+\frac{f(1)}{A(1)}}\right] \frac{1}{\kappa p_{i} A(1)}\left[\tilde{c}_{0}^{1-\sigma}-\tilde{c}^{1-\sigma}\right] .
$$

The implications for the symmetric equilibrium are clear. Only in the case of $\log$ utility $(\sigma=1)$ there is no incentive to deviate from a full pass-through equilibrium. However, when $\sigma>1$ there is a tendency to overshoot in the most likely case that aggregate consumption is a positive function of the productivity level. In our simulations, this effect proves to be very small for any reasonable value of $\sigma$. 


\section{Markup and Value of Extensive Margin}

Recall our definitions for the variables $v_{i t}$ and $\bar{v}_{i t}$ :

$$
\begin{gathered}
v_{i t}=\beta E_{t} \lambda_{i t+1} A(1)\left(\frac{p_{i t+1}}{\tilde{p}}\right)^{-\gamma} \tilde{c}+\beta E_{t} v_{i t+1} \\
\bar{v}_{i t}=\lambda_{i t}\left(\frac{p_{i t}}{\tilde{p}}\right)^{-\gamma} \tilde{c}+v_{i t} .
\end{gathered}
$$

Plugging (C.1) into (C.2), we get

$$
\bar{v}_{i t}=\lambda_{i t}\left(\frac{p_{i t}}{\tilde{p}}\right)^{-\gamma} \tilde{c}+\beta E_{t} \lambda_{i t+1} A(1)\left(\frac{p_{i t+1}}{\tilde{p}}\right)^{-\gamma} \tilde{c}+\beta E_{t} v_{i t+1} .
$$

Next, we lead (C.2) by one period and plug it into (C.3). After rearranging we obtain:

$$
\lambda_{i t}\left(\frac{p_{i t}}{\tilde{p}}\right)^{-\gamma} \tilde{c}+\beta E_{t} \lambda_{i t+1}[A(1)-1]\left(\frac{p_{i t+1}}{\tilde{p}}\right)^{-\gamma} \tilde{c}=\bar{v}_{i t}-\beta E_{t} \bar{v}_{i t+1} .
$$

We define the gross markup as $m k_{i t}=p_{i t} / m c_{i t}$ where $m c_{i t}=w_{t} / z_{i t}$. This implies:

$$
\lambda_{i t}=m c_{i t}\left[m k_{i t}-1\right]
$$

Plugging into (C.4) and applying a first-order Taylor expansion around the steadystate yields:

$$
\begin{gathered}
\widehat{\Phi}_{i t}+\beta[A(1)-1] E_{t} \widehat{\Phi}_{i t+1} \approx \bar{v}_{i}\left[\widehat{\bar{v}}_{i t}-\beta E_{t} \widehat{\bar{v}}_{i t+1}\right] \\
\text { where } \\
\widehat{\Phi}_{i t}=\left(\frac{p_{i}}{\tilde{p}}\right)^{-\gamma} \tilde{c}\left[m k_{i} \widehat{m k}_{i t}+\left[m k_{i}-1\right] \widehat{m c}_{i t}-\gamma\left[m k_{i}-1\right] \widehat{p}_{i t}\right] .
\end{gathered}
$$

All the hatted variables indicate percentage deviations from steady state. Next, we simplify (C.5). The second term on the left hand side of (C.5) is multiplied by $[A(1)-1]$, which is very small for almost all distributional assumptions. We therefore drop it as it is dwarfed by the other terms. Similarly, the last two terms in (C.6) are 
multiplied by $\left[m k_{i}-1\right]$. As the steady state markup is very low in our benchmark, any movements in $\widehat{m c}_{i t}$ and $\widehat{p}_{i t}$ will be dwarfed by fluctuations in $\widehat{m k}_{i t}{ }^{27}$ Therefore, after setting $\tilde{p}=p_{i}$ and $\tilde{c}=1$ to simplify the exposition without any loss of generality, we obtain the following approximate relation:

$$
\widehat{m k}_{i t} \approx-\frac{\bar{v}_{i}}{m k_{i}}\left[\beta E_{t} \widehat{\bar{v}}_{i t+1}-\widehat{\bar{v}}_{i t}\right]
$$

\section{Persistence of the Shock and Learning}

It is conceivable that when firms experience a productivity shock, they find it hard to recognize whether the nature of the shock is temporary or highly persistent. While in many models such a distinction is inconsequential or very secondary, in our setup the perceived persistence of the shock is important for the dynamics of the price response. We now briefly illustrate how uncertainty about the persistence of the productivity shock affects the optimal pricing decision of a firm.

One possible way to model such uncertainty would be to let the persistence parameter in the marginal cost process be unknown, and allow Bayesian agents to learn about this parameter. Agents, endowed with prior beliefs about $\rho$, would then use Bayes' law to optimally update their beliefs and derive their posterior distribution for the persistence parameter. Here, however, we pursue a different approach to capture uncertainty. We model the learning process of the firm by using a simple linear Kalman filtering framework. Agents do not observe the true marginal cost shock. Instead, they observe a noisy signal from which they try to infer what is the true state of the underlying marginal cost process is. Using the Kalman filter algorithm, agents generate recursive forecasts of the true underlying state process.

Uncertainty in the model is captured explicitly in a standard way by the following two processes:

$$
\begin{aligned}
& m c_{t}=m c_{t}^{*}+\varepsilon_{t}, \varepsilon_{t} \sim N\left(0, \sigma_{\varepsilon}^{2}\right) \\
& m c_{t}^{*}=\rho m c_{t-1}^{*}+v_{t}, v_{t} \sim N\left(0, \sigma_{v}^{2}\right)
\end{aligned}
$$

${ }^{27}$ This is not true for all parameterizations. For example, when $\beta=0$, we know that $m k_{i}=\frac{\gamma}{\gamma-1}$, which is significantly larger than 1. 
where $m c$ is observable by agents, while $m c^{*}$ represents the true unobservable state of the underlying marginal cost process. In other words, $v$ is a fundamental persistent shock, while $\varepsilon$ can be described as noise. Here, the structure of the model is known by agents. More explicitly, $\rho$ is known by all agents. ${ }^{28}$ Equations (D.1) and (D.2) are the observation and measurement equations, respectively. ${ }^{29}$

For this exercise we set $\rho=1$. Hence, $\varepsilon$ shocks are purely temporary while a $v$ shock has a permanent effect on the marginal cost. However, agents cannot distinguish between the source of the disturbance. The important elements of the filtering process applied to (D.1) and (D.2) can be summarized as follows:

$$
\begin{aligned}
m c_{t \mid t}^{*} & =m c_{t \mid t-1}^{*}+K\left(m c_{t}-m c_{t-1 \mid t-1}^{*}\right) \\
K & =\frac{P}{P+\sigma_{\varepsilon}^{2}} \\
\sigma_{v}^{2} & =\frac{P^{2}}{P+\sigma_{\varepsilon}^{2}}
\end{aligned}
$$

where equation (D.3) indicates that agents update their beliefs about $m c_{t}^{*}$ after they observe $m c_{t}$. As is common in the literature, in equation (D.4) we use the steady state level of the Kalman gain process, $K . P$ is the steady state level of the variance of $m c^{*}$, which solves the Riccati equation given in (D.5).

We simulate our model under the maintained assumption of uncertainty about the nature of the shock. We use our benchmark parametrization described at the beginning of section 5.1, and analyze the responses under the following signal-tonoise ratio values: $\frac{\sigma_{v}^{2}}{\sigma_{\varepsilon}^{2}}=\{0.2,0.02,0.002\} .{ }^{30}$ We simulate a $5 \%$ positive fundamental (i.e. permanent) shock to $m c^{*}$ and present the reaction of $p_{i}$.

Under this setup, when the firm observes a jump in its marginal cost, it is unclear about its persistence. Since we assume that $\frac{\sigma_{v}^{2}}{\sigma_{\varepsilon}^{2}}<1$, the firm initially puts a higher weight on the possibility that the shock is temporary, and accordingly only partially

\footnotetext{
${ }^{28}$ We assume that all the standard Kalman filter assumptions hold. For a general discussion, see, for example, Hamilton (1994, section 13.1).

${ }^{29}$ Equation (D.1) is only part of the observation system, since agents also observe other variables, aside from $m c$, such as $c, l$ etc. This point is taken into account when solving for the optimal response in prices.

${ }^{30}$ The solution to (D.4) and (D.5) will depend solely on the signal-to-noise ratio parameter.
} 


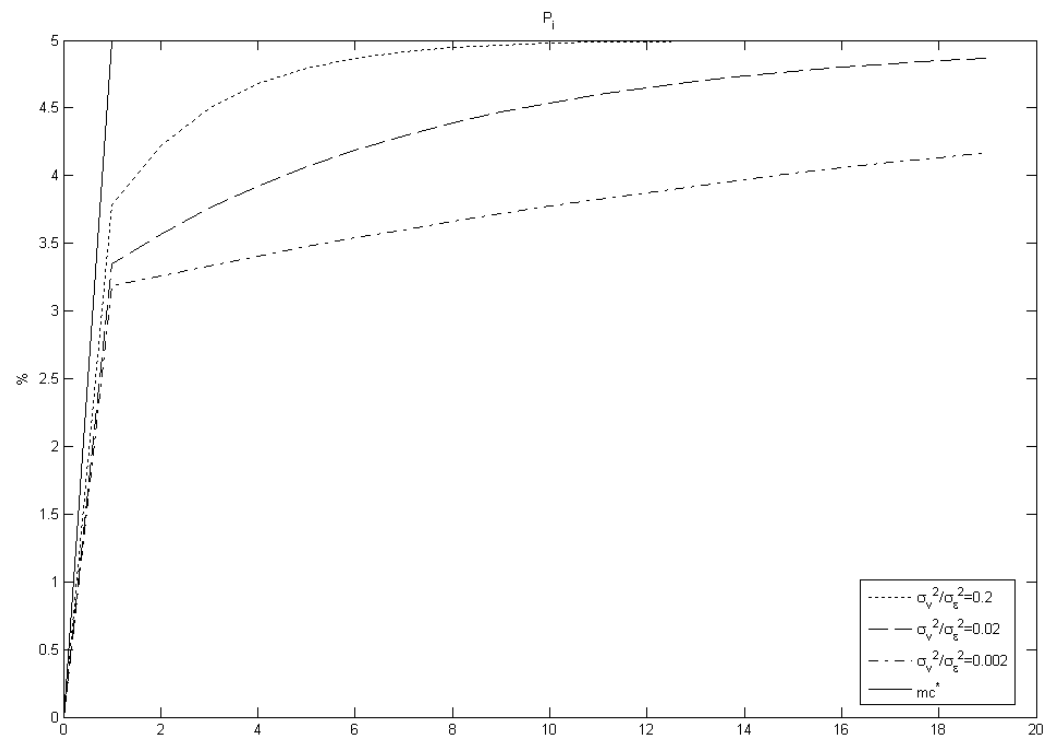

Figure D.1: Permanent shock to marginal cost under shock uncertainty.

passes through the observed marginal cost increase into prices. However, as the firm continues period after period to observe a high level of $m c$, it updates its belief and eventually converges to full pass-through as it becomes more convinced that the shock is permanent. Not surprisingly, the response of prices is more delayed the higher the ratio of relative volatilities $\frac{\sigma_{v}^{2}}{\sigma_{\varepsilon}^{2}}$. 


\section{Liste des cahiers de recherche publiés par les professeurs 2007-2008}

\section{Institut d'économie appliquée}

IEA-07-01 Moez Bennouri, Robert Clark, and Jacques Robert. Consumer Search and Information Intermediaries, 32 pages.

IEA-07-02 Jean-François Angers, Denise Desjardins, Georges Dionne, Benoit Dostie and François Guertin. Poisson Models with Employer-Employee Unobserved Heterogeneity: An Aplicatin to Absence Data, 25 pages.

IEA-07-03 Georges Dionne, Robert Gagné and Abdelhakim Nouira. Determinants of Insurers' Performance in Risk Pooling, Risk Management, and Financial Intermediation Activities, 36 pages.

IEA-07-04 Stefan Ambec et Paul Lanoie. When and why does it pay to be green?, 40 pages.

IEA-07-05 Christos Koulovatianos, Leonard J. Mirman and Marc Santugini. Optimal growth and uncertainty: learning, 36 pages.

IEA-07-06 Paul Lanoie, Jérémy Laurent-Lucchetti, Nick Johnstone, Stefan Ambec. Environmental Policy, Innovation and Performance: New Insights on the Porter Hypothesis, 40 pages.

IEA-07-07 Paul Lanoie et Daniel Llerena. Des billets verts pour des entreprises agricoles vertes?, 35 pages.

IEA-07-08 Taoufik Bouezmarni, Jeroen V.K. Rombouts. Semiparametric Multivariate Density Estimation for Positive Data Using Copulas, 29 pages.

IEA-07-09 Luc Bauwens, Arie Preminger and Jeroen V.K. Rombouts. Theory and Inference for a Markov Switching Garch Model, 26 pages.

IEA-07-10 Taoufik Bouezmarni, Jeroen V.K. Rombouts. Nonparametric Density Estimation for Multivariate Bounded Data, 31 pages.

IEA-07-11 Georges Dionne and Benoit Dostie. Estimating the effect of a change in insurance pricing regime on accidents with endogenous mobility, 24 pages.

IEA-07-12 Dominique Guégan and Justin Leroux. Forecasting chaotic systems: The role of local Lyapunov exponents, 6 pages.

IEA-07-13 Jérémy Laurent-Lucchetti and Justin Leroux. Choosing and Sharing, 21 pages. 
IEA-07-14 Jérémy Laurent-Lucchetti and Justin Leroux. Why Me? Siting a Locally Unwanted Public Good, 16 pages.

IEA-07-15 Mohammed Bouaddi and Jeroen V.K. Rombouts. Mixed exponential power asymmetric conditional heteroskedasticity, 25 pages. 